Illinois State University

ISU ReD: Research and eData

Theses and Dissertations

4-28-2014

\title{
Children's Experiences with Relational Aggression and Their Disclosure to their Friends: An Evaluation of Dyads, Friendship Networks, and Peer Groups
}

Jayme Lee Jones

Illinois State University, jaymejones523@gmail.com

Follow this and additional works at: https://ir.library.illinoisstate.edu/etd

Part of the Psychology Commons

\section{Recommended Citation}

Jones, Jayme Lee, "Children's Experiences with Relational Aggression and Their Disclosure to their Friends: An Evaluation of Dyads, Friendship Networks, and Peer Groups" (2014). Theses and Dissertations. 184.

https://ir.library.illinoisstate.edu/etd/184

This Dissertation is brought to you for free and open access by ISU ReD: Research and eData. It has been accepted for inclusion in Theses and Dissertations by an authorized administrator of ISU ReD: Research and eData. For more information, please contact ISUReD@ilstu.edu. 


\section{CHILDREN'S EXPERIENCES WITH RELATIONAL AGGRESSION AND THEIR \\ DISCLOSURE TO THEIR FRIENDS: AN EVALUATION OF DYADS, FRIENDSHIP NETWORKS, AND PEER GROUPS}

Jayme L. Jones

91 Pages

August 2014

Relational aggression is a devastating problem that has long-lasting consequences for children, especially girls. Although some studies have found that girls who disclose more to their friends experience higher levels of relational aggression, other studies have found that those who experience aggression disclose less than those who do not experience aggression. It is possible that this difference is related to the type of friendships being assessed and who is describing the friendship (i.e., self-report versus peer report). The purpose of this study was to expand on previous research regarding self-disclosure and relational aggression by addressing these differences. First, this study addressed children's experiences in three relationship contexts: dyadic friendships, friendship networks, and peer groups. This study also included both self- and peer-reports. It was hypothesized that the association between relational aggression and self-disclosure would depend on the specific relationship context being assessed. The study included 62 girls from a community-based social organization and 37 girls from a high school setting. Each participant completed a peer nomination form and self-report measures regarding her friendships with other girls. Results showed that perpetration of relational aggression was positively associated with being victimized by relational aggression, especially 
within dyadic relationships and friendship networks. Disclosing personal information was positively associated with being a confidant to other girls, especially within friendship networks.

Victimization and disclosing were positively correlated among the peer group in the school sample. Differences between the community sample and school sample were primarily seen within the peer group. Implications for interventions to reduce relational aggression are discussed. 
CHILDREN'S EXPERIENCES WITH RELATIONAL AGGRESSION AND THEIR

DISCLOSURE TO THEIR FRIENDS: AN EVALUATION OF DYADS,

FRIENDSHIP NETWORKS, AND PEER GROUPS

JAYME L. JONES

A Dissertation Submitted in Partial

Fulfillment of the Requirements

for the Degree of

DOCTOR OF PHILOSOPHY

Department of Psychology

ILLINOIS STATE UNIVERSITY

2014 
Copyright 2014 Jayme L. Jones 


\section{CHILDREN'S EXPERIENCES WITH RELATIONAL AGGRESSION AND THEIR DISCLOSURE TO THEIR FRIENDS: AN EVALUATION OF DYADS, FRIENDSHIP NETWORKS, AND PEER GROUPS}

JAYME L. JONES

COMMITTEE MEMBERS:

Jeffrey H. Kahn, Chair

Renée M. Tobin

Marla Reese-Weber

Susan Sprecher 


\section{ACKNOWLEDGMENTS}

Over the past few years, I have received more support and encouragement than I could have ever hoped for. I have grown as a researcher and a person, and I owe that to the many people who have graciously provided me with their time and knowledge. It is with immense gratitude that I acknowledge their efforts and encouragement.

I would first like to thank my dissertation chair, Dr. Jeffrey Kahn. He has been with me since the very beginning and has helped me "think big" and also keep my ideas manageable and grounded. His help, support and guidance has gotten me though when things went well and as planned, and his encouragement kept me going when things did not go as planned and I felt discouraged. My dissertation would not have been possible without his knowledge, persistence, and never-ending optimism. I am very appreciative of the time he spent with me throughout this entire process.

I would also like to thank my wonderful and knowledgeable dissertation committee: Dr. Marla Reese-Weber, Dr. Susan Sprecher, and Dr. Renée M. Tobin. Their ideas, feedback, and encouragement have helped this project grow from a thought to an accomplishment. Their contributions encouraged me to consider ideas from a new perspective. Their insight has truly helped shape what this dissertation is today.

I am also appreciative of those who helped with data collection. I would like to thank Diana Steakley-Freeman for her efforts in helping me work the participants. I would also like to thank Sandy Clark for her willingness to join me on the long drives around the state and her sense of humor along the way. 
And finally, I would like to thank my family for their encouragement to begin this endeavor and their support and understanding throughout the process. I would like to thank Lewis Mazzone for his never-ending belief in my ability. I especially want to thank my mother, Christie Jones, who has listened to me, cried with me, and celebrated with me at every step. Her belief that with a strong work ethic and dedication you can accomplish your goals inspired me to continue learning. Her example set me on this path and will continue to guide me as I continue in my career.

J. L. J. 


\section{CONTENTS}

CHAPTER

Dyads, Networks, Cliques, and Peer Groups

Definition

Gender Differences

Associated Risks and Outcomes

Developmental Trend

Relational Aggression in Friendship Networks And Peer Groups 
Association Between Relational Aggression and Self-Disclosure

Summary

Purpose and Hypotheses

III. METHOD

Participants

Measures of Victimization, Bullying, and Self-Disclosure

Friendship Networks

Dyadic Friendships

Procedure

Community Sample

Overview of Data Analyses

Dyadic Friendships

Community Sample

Friendship Networks

Peer Groups

Community Sample 
Summary of Results: Comparing Two Samples and Three Relationship Contexts

Limitations

Implications for Future Research

67

Implications for Theory and Practice

70

REFERENCES

APPENDIX A: Items Included In Peer Nomination Form

APPENDIX B: Community Sample Parent Consent Form

80

APPENDIX C: Community Sample Assent Form

83

APPENDIX D: Community Sample Debriefing Form

APPENDIX E: School Sample Parent Consent Form

APPENDIX F: School Sample Assent Form

89

APPENDIX G: School Sample Debriefing Form 


\section{TABLES}

\section{Table}

1. Association Between Behavior and Type of Relationship Being Assessed

2. Hypothesized Associations Between Relational Aggression and Self-Disclosure in Dyadic Friendships

3. Hypothesized Associations Between Relational Aggression and Self-Disclosure in Friendship Networks and Peer Groups

4. Measures Used for Behaviors Based on Type of Relationship Being Assessed

5. Means and Standard Deviations for Self-Reports and Peer-Reports for Community and School Samples

6. Multitrait-Multimethod Analysis for Best-Friend Dyadic Friendships

7. Means and Standard Deviations for Friendship Networks for Community and School Samples

8. Correlation Coefficients for Friendship Networks

9. Number of Nominations for Each Variable for Community Sample Participants 


\section{CHAPTER I}

\section{THE PROBLEM AND ITS BACKGROUND}

\section{Statement of the Problem}

Bullying is a widespread problem that affects nearly one-third of children on a daily to weekly basis (Hall, 2006), with prevalence rates for relational aggression suggesting nearly onehalf of children experience this particular type of aggression (Wang, lannotti, \& Nansel, 2009). It is reported that bullying will affect up to $80 \%$ of all children at some point in childhood or adolescence (Casey-Cannon, Hayward, \& Gwen, 2001). Olweus (2003) defines bullying as the repeated threatening or infliction of harmful behaviors that create a power imbalance between people. While physical aggression has received a lot of attention from researchers, a growing body of research has examined relational aggression. Relational aggression is a form of bullying that is intended to harm children's relationships. Children may be threatened with the loss of the friendship or isolation from a group (Grotpeter \& Crick, 1996).

Although numerous studies have indicated that girls are more likely to experience relational aggression than boys are (Grotpeter \& Crick, 1996; Murray-Close, Ostrov, \& Crick, 2007), other studies have shown equal levels of victimization for boys and girls (Archer \& Coyne, 2005; Henington, Hughes, Cavell, \& Thompson, 1998). However, given that girls have more extended dyadic relationships, place more value on closeness and dependence, and worry more about abandonment (Rose \& Rudolph, 2006), relational aggression is likely a more socially damaging experience for girls than it is for boys. Furthermore, research examining the 
psychological outcomes of relational aggression has shown it to be just as detrimental to children as physical aggression is. Children who are relationally victimized experience increased depression, anxiety, and loneliness, and lower academic achievement (Nishina, Juvonen, \& Witkow, 2005). Victims of relational aggression also show increased avoidance of social situations and withdrawal from previously enjoyed activities, which further influences their social-emotional well-being, peer relations, and the development of future relationships (Nishina et al., 2005).

Given the potentially devastating outcomes associated with relational aggression, a better understanding of relational aggression is vital. A main focus of previous research on relational aggression has been to examine the friendships of relationally aggressive girls (Grotpeter \& Crick, 1996; Murray-Close et al., 2007). Specifically, self-disclosure between friends has been examined in a small number of studies (Grotpeter \& Crick, 1996; Jones, Kahn, \& Landau, 2011; Murray-Close et al., 2007) because of the possibility that disclosing personal information to relationally aggressive girls would give those girls power over their victims, for example, by threatening to reveal this disclosed information to others. However, research has often resulted in incompatible results. For example, Grotpeter and Crick concluded that relationally aggressive friendships were characterized by high levels of intimacy, as defined by high levels of disclosure from a friend. In contrast, Jones et al. (2011) found that girls who were victimized by relationally aggressive friends disclosed less than girls who were not victimized. Part of this inconsistency may stem from focusing either on the experience of the bully or the experience of the victim, and it may also be due to methodological differences in studying these phenomena (i.e., research on dyads versus the broader peer group). For example, Grotpeter and Crick examined dyadic relationships from the perspective of the aggressor, whereas Jones et al. 
focused on peer groups and the perspective of the bully. These methodological differences might account for the discrepancies in results regarding the friendships of victims and bullies.

Given the contradictory findings, future research on the topic of children's selfdisclosure and their experiences with relational aggression is warranted. There is agreement that intimacy and self-disclosure are central components of all friendships (Grotpeter \& Crick, 1996; Jones et al., 2011), but these are especially important concepts for understanding relationally aggressive friendships, as there appears to be a complex association between them. However, the exact association between disclosure and relational aggression is unclear because of discrepancies in focus on the bully versus the victim as well as discrepancies in focus on the peer group versus a single friend.

The purpose of this study was to examine the association between relational aggression and self-disclosure for both bullies and victims within dyadic friendships, friendship networks, and peer groups. Specifically, this study assessed whether female victims of relational aggression disclose more to their close friends, friendship networks, and peer groups than nonvictimized girls. Similarly, the disclosure of bullies was addressed to assess whether they disclose less to their close friends, friendship networks, and peer groups in general than their nonrelationally aggressive peers. 
CHAPTER II

\section{REVIEW OF RELATED LITERATURE}

In this chapter I review background research on friendships and peer groups, relational aggression, and self-disclosure. I will first begin by discussing the development of dyadic friendships and friendship networks. I will then define relational aggression and explain how it compares to other types of aggression, along with a description of the developmental trends, gender differences, and negative outcomes of relational aggression. I will also discuss how relational aggression is measured in research and describe past research on relational aggression. I will then discuss self-disclosure and how it relates to friendship development. Finally, I will discuss the association between relational aggression and self-disclosure. This association is the focus of this proposed study.

\section{Friendships and Their Development}

\section{Dyads, Networks, Cliques, and Peer Groups}

Friendships are the mutual sharing of a relationship by two or more people (Bukowski \& Hoza, 1989). A friendship between two people is called a dyadic friendship. Multiple integrated dyadic relationships are referred to as a friendship network. Within a friendship network, people may have multiple dyadic relationships with varying levels of closeness. Additionally, while it is possible that members of the friendship network will have at least a casual friendship with all members of the network, it is not required. A friendship network is likely to have many reciprocated dyadic relationships, as well as acquaintances and possibly people who dislike another member of the network (Newcomb \& Bagwell, 1995). 
A special type of friendship network called a clique is a relatively small network that is unique in that members' relationships are typically limited to the clique and all members of the group identify as being friends with every other member of the group (Hallinan, 1980). Members of a clique are also typically close, the same age/grade, and of the same race and socio-economic status. Membership may be exclusive. However, cliques may also have liaisons who serve as the link between two or more cliques, connecting members of one clique to those of another (Hallinan, 1980).

Peer groups are the total collection of relationships, such as those within a class, a school, an extracurricular organization, or a community-based organization. They contain dyadic relationships, friendship networks, cliques, and the relationships among all three. Peer groups also include children who do not have close relationships with each other. Children's statuses within their peer group may be related to their individual friendships, network, or clique membership, but popularity, defined as high social status within a peer group, is not identical to friendship. Popularity is acceptance by a peer group, but acceptance does not necessarily result from friendship (Bukowski \& Hoza, 1989). In fact, children who exhibit aggressive behaviors often see their popularity grow through middle school, approximately ages 12 through 14 , whereas their friendships decrease in both number and quality (Rose, Swenson, \& Waller, 2004; Witvliet et al., 2009).

\section{Development of Dyadic Friendships}

Friendship development can be thought of as a dynamic process that encompasses three phases. In the first phase, the initiation phase, two people move from being acquaintances to beginning their friendship (Adams \& Blieszner, 1994). The initiation phase of a relationship begins with attraction and getting to know each other. Gottman (1983) showed that the initiation phase is also dependent on multiple child social behaviors. These behaviors include the 
exchange of factual information, self-disclosure (sharing private information, such as feelings and beliefs when asked), communication clarity, reciprocity in joking, and conflict resolution. This phase requires repeated interactions in which people can begin to evaluate the other on their personal characteristics, including likeability, communication, and ultimately compatibility. This phase is also limited by certain geographic and contextual considerations, including proximity, demands placed on each person, and available resources for maintaining interactions (Blieszner \& Adams, 1992). At the conclusion of this phase, if two people have decided they would not like to expand their relationship, they either discontinue contact or remain as acquaintances. However, two people who have evaluated the other as a potential friend enter the second phase, the maintenance phase (Adams \& Blieszner, 1994).

The maintenance phase is typically the longest phase of a relationship as it accounts for the majority of all shared activities, experiences, and the emotional closeness of the relationship, although the emotional closeness can range from a casual friend to a best-friend relationship. This phase involves maintaining interest in the relationship and emotional closeness toward the other through identifying deeper similarities (i.e., values and beliefs), providing social and emotional support, developing trust, and solving problems effectively. Another task of the maintenance phase is to evaluate the benefits of the relationship continuously. This evaluation is dependent on each person's other friendships, the possibility of developing other relationships, and the person's social circumstances (e.g., support received from relationships, need for a friendship), and this evaluation is used to decide whether the positive outcomes of the relationship outweigh any negative consequences. Relationships that provide benefits are strengthened, stay in the maintenance phase, and continue to be evaluated for any changes. Relationships that cause harm or fail to provide benefits, in contrast, are weakened. When the relationship is weakened enough, it will enter the final phase, the 
dissolution phase. In this phase, one or both partners end the relationship (Adams \& Blieszner, 1994).

\section{Development of Friendship Networks}

There is a similar process for the development of friendship networks. Networks typically include numerous dyadic relationships and begin when either multiple dyadic relationships join together or an individual joins an already formed dyadic relationship. From here, the network develops by adding additional individuals or dyads. The maintenance phase of friendship networks involves the same process found with dyadic relationships but is inherently more complicated, as it includes all members of the network in the evaluation of the relationship. Entire friendship networks rarely enter the dissolution phase, but individuals or dyads may remove themselves, or be removed by others, from the group (Adams \& Blieszner, 1998). With the development of dyadic friendships and friendship networks, though, comes the potential for conflict and harm within the friendship. With this in mind, I now turn to a discussion of relational aggression.

\section{Relational Aggression}

\section{Definition}

Relational aggression is defined broadly as harming someone by damaging or manipulating relationships or negatively influencing their social status within a peer group. More specifically, relational aggression harms children by targeting their feelings of acceptance and inclusion in either a dyadic friendship or a group. Relationally aggressive behaviors include spreading or threatening to spread secrets, threatening to end the friendships, taunting, and teasing (Grotpeter \& Crick, 1995). These behaviors can occur in any context, including in person, behind one's back, and online. 
Relational aggression has often been confused with other types of aggression, including indirect aggression, social aggression, and verbal aggression (Archer \& Coyne, 2005). Indirect aggression is a type of aggression that attempts to inflict pain without detection by the victim, as if there were no attempt to hurt the victim. Recent definitions focus on the goal of indirect aggression as to harm someone's social status through a third party so as to avoid being identified as the aggressor. Indirect aggression is a covert type of aggression that may take many forms, including both verbal and physical forms (Archer \& Coyne, 2005). Social aggression is aimed at harming someone's self-esteem and social status through the use of covert or overt acts. Social aggression also includes the use of nonverbal harmful behaviors, such as eye rolling. Verbal aggression includes acts such as insults and is limited to verbal behaviors. Relational aggression can take both covert and overt forms as the focus of relational aggression is not on the form but rather on the intention to harm social relationships (Archer \& Coyne, 2005). As such, there is much overlap between relational aggression, indirect aggression, and social aggression. However, there are also forms of relational aggression that are distinctly relational, such as threatening to end a dyadic relationship. In this case, the victim knows who the aggressor is so it is not indirect, and the victim's social status within the peer group is not automatically threatened so it is not necessarily social aggression. For this study, relational aggression will be defined through its intent, that is, harming one's relationships and social status. Although specific acts or descriptions of relational aggression may overlap with other types of aggression, the intent will be consistent.

Although the intent of relational aggression remains the same, it can occur in a variety of situations, such as either a connected or isolated setting. On one hand, connected victimization occurs when a victim is liked by peers and has a secure status among their peers (Zimmer-Gembeck, Pronk, Goodwin, Mastro, \& Crick, 2013). Isolated victimization, on the other 
hand, occurs when a victim is more rejected and disliked by peers. Relationally aggressive behaviors have also been described as falling into five different categories. Pronk and ZimmerGembeck (2010) asked adolescents to describe their experiences as a bully, a victim, or both. Based on these experiences, the authors determined that relational aggression includes: spreading rumors and gossip, excluding others or ending friendships, social intimidation, notes and cyber bullying, and exhibiting inconsistent and unpredictable friendship (i.e., being well liked by a peer one day, and much less liked the next, but not having the friendship completely ended). Interestingly, although cyber bullying appears to be increasing among children and adolescents, Pronk and Zimmer-Gembeck (2010) reported that adolescents are more likely to experience relational aggression consistent with the other four categories than they are to experience cyberbullying. This finding suggests that girls are more likely to experience relational aggression that is either direct or occurs directly within the friendship network or peer group, rather than aggression that occurs through more indirect means, such as through social media.

\section{Gender Differences}

There are significant gender differences in experiences with relational aggression.

Although boys and girls engage in roughly equal levels of relational aggression during preschool, their experiences start to diverge in early elementary school, with girls becoming more likely than boys to experience relational aggression and to be negatively affected by relational aggression (Rose \& Rudolph, 2006; Wang et al., 2009). There are many reasons this divergence may occur. One explanation is that boys and girls value different aspects of friendships. Whereas boys have self-interest goals and value friendships for shared interests and activities, girls have more prosocial goals and value friendships for their emotional closeness, security, and acceptance (Rose \& Rudolph, 2006). Given that both physical and relational aggression are about having power over others, one must harm another in a way that is personally damaging in 
order to gain power (Olweus, 1991). For boys, who value strength and dominance, power is derived by being physically in control, and victims come to have a weaker status than their aggressors through this physical power imbalance. However, physical aggression, although still harmful for girls, does not pose the same threat for girls, as girls do not have the same interests and values as boys. For girls, power comes from harming what is important in girls' relationships--emotional closeness, feelings of belonging, and group membership (Rose \& Rudolph, 2006). Victims come to have a weaker status because their relationships are being manipulated or threatened. Therefore, these key differences between boys' and girls' relationships influence the type of aggression they may experience and find hurtful. Indeed, girls report that socially aggressive behaviors are more hurtful than boys do, and girls view socially aggressive children as being angrier than boys do (Galen \& Underwood, 1997). This pattern is further supported by Pronk and Zimmer-Gembeck (2010), who found that adolescent girls are more likely than boys to experience victimization within a close friendship, with that victimization focusing on maintaining exclusivity in the relationship. Boys, however, are more likely to be excluded from a larger peer group with aggression focusing on establishing masculinity or athletic skill. Girls are also at a greater risk than are boys for experiencing negative outcomes related to being both a victim and aggressor of relational aggression (Crick \& Grotpeter, 1995).

\section{Associated Risks and Outcomes}

Being the victim of relational aggression poses many risks for children. Children who are victimized have a greater risk of loneliness, social anxiety and avoidance, depression, and medical symptoms such as headaches and more frequent illness (Crick \& Grotpeter, 1995; Jones et al., 2011). Although it was once believed that the outcomes of relational aggression were less severe for victims than were the outcomes of physical aggression, recent research has 
supported that the potential risks of relational aggression are extremely devastating and just as harmful for the victims (Prinstein, Boergers, \& Vernberg, 2001). Despite this, relational aggression is still often considered to be more normative and a typical part of growing up than is physical aggression by both children and their parents (Crick, Bigbee, \& Howes, 1996; Werner \& Grant, 2008).

Interestingly, the negative outcomes of relational aggression are not limited to the victims. Relationally aggressive bullies are at just as great of a risk for many social and emotional difficulties as their victims. For example, youth who engage in high levels of relational aggression are at an increased risk for depression, loneliness, peer rejection, and social maladjustment (Crick \& Grotpeter, 1995). Relationally aggressive children also have lower likeability ratings than their non-relationally aggressive peers; however, lower likeability is not equivalent with low popularity, as children who exhibit relationally aggressive behaviors experience popularity increases over time (LaFontana \& Cillessen, 2002).

\section{Developmental Trend}

Relational aggression is seen early in childhood, often occurring between preschool children (Crick, Cases, \& Ku, 1999), and continuing to increase in frequency as children age (Murray-Close et al., 2007). Pellegrini and Long (2003) suggested that relational aggression increases through late elementary school and early middle school before decreasing and then plateauing during late middle school into high school; however, this pattern may reflect a change in presentation of relational aggression rather than an actual decrease in level of aggression. For example, as children transition into middle school and high school, they spend less time in the direct supervision of teachers and parents who are often asked to provide reports of the frequency of relational aggression. Additionally, as children enter adolescence they often rely less on parents and teachers and more on friends for support when experiencing 
difficult situations and interpersonal conflicts, such as relational aggression (Savin-Williams \& Berndt, 1990). Further, aggressive acts are more likely to be committed by children with sophisticated social skills and understanding of cognitions and emotions (Sutton, Smith, \& Swettenham, 1999). It is plausible that as adolescents develop more advanced social skills, they are better able to understand the intricacies of relational aggression and can better hide their aggressive behaviors. Therefore, children and adolescents may continue to engage in relationally aggressive behaviors as much as they did when they were younger, but their behaviors may not be as frequently observed by others.

\section{Measures of Relational Aggression}

Research examining relational aggression has primarily used two approaches. The first approach is to have children complete a rating scale regarding their experiences. One of the most commonly used measures is the Friendship Qualities Measure (FQM; Grotpeter \& Crick, 1996), a self-report scale developed to measure 14 qualities of children's dyadic friendships, including "relational aggression toward others" (a measure of aggression) and "relational aggression towards friends" (a measure of victimization). Relational aggression victimization is also measured through the Social Experiences Questionnaire- Self Report (SEQ-S; Crick \& Grotpeter, 1996). This 15 -item scale includes a subscale focused on children's experience with relational and overt victimization, along with their experiences of prosocial behaviors. Unlike the Friendship Qualities Measure, the Social Experiences Questionnaire focuses on children's experiences in their peer group instead of their experiences with a specific friend. However, the relational aggression subscale is limited compared to the subscales on the Friendship Qualities Measure as being a bully is not assessed.

Another approach to measuring relational aggression is through the use of peer nominations that assess children's sociometric statuses within their peer group. For this 
approach, participants are provided a list of the other children, typically children in their class, school, or peer group, and are asked to identify students who exhibit a particular characteristic, such as aggression. This approach allows researchers to identify students who exhibit high or low levels of specific characteristics. To identify relationally aggressive girls, studies typically have children nominate others on a number of behaviors that are indicators of relational aggression and then add nominations on each behavior to determine girls who are relationally aggressive (Grotpeter \& Crick, 2006).

\section{Relational Aggression in Dyadic Friendships}

A primary focus of relational aggression research has been on examining relational aggression within dyadic friendships, typically a best-friend relationship (Grotpeter \& Crick, 1996; Murray-Close et al., 2007). This method is usually approached through peer nominations of best friends and bullies and self-report measures regarding children's specific experiences with relational aggression. This approach has provided a great deal of information regarding relationally aggressive friendships. For example, Grotpeter and Crick (1996) examined whether the relationships of girls who engaged in relationally aggressive behaviors were different from the friendships of girls who did not engage in relationally aggressive behaviors by assessing the quality of dyadic best-friend friendships of third through sixth grade students using the FQM. In this study, girls were asked to nominate up to three peers for five different behaviors that were an indicator of relational aggression. Girls' nominations for each behavior were summed and standardized for each class. Scores one standard deviation above the sample mean were considered relationally aggressive. Girls were also asked to identify their three best friends, and based on these reports the authors assigned each child to complete the FQM for a mutual friend. In addition to the FQM, girls also completed the Importance of Friendship Qualities Measure, which assesses how upset children would be if their friend violated each of the 
friendship qualities outlined in the FQM. Results showed that friendships of relationally aggressive girls were similar to nonaggressive girls on many friendship qualities, including validation, caring, and companionship. However, relationally aggressive girls and their best friend (whose status as a bully or nonaggressive girl was not identified) both reported higher levels of exclusivity than nonaggressive girls. Bullies also reported higher levels of friend intimacy, and their friends reported higher levels of relational aggression within the friendship than did friends of nonaggressive girls. These results indicated that relationally aggressive girls have dyadic friendships that are similar to the friendship of nonaggressive girls on many qualities, but they differ from nonaggressive girls' friendships on a few key aspects, including exclusivity and possibly friend intimacy.

\section{Relational Aggression in Friendship Networks and Peer Groups}

Although relational aggression has largely been examined in dyadic relationships, relational aggression is not limited to dyads. Rather, relational aggression can also occur within friendship networks and large peer groups (e.g., students attending the same school). In fact, some forms of relational aggression, such as exclusion from a group, by nature require more than two people, and up to $50 \%$ of victimization may occur outside of the dyad (Crick \& Grotpeter, 1995). Archer and Coyne (2005) suggested that relational aggression in a group, such as a friendship network, may have a different goal than relational aggression in a dyad. For example, relational aggression in a group is more likely to damage one's social status and multiple friendships, whereas relational aggression in a dyad is more likely to threaten a specific relationship. It is, therefore, important to address relational aggression within the peer group to fully understand how relational aggression is associated with children's relationships.

One focus of previous research on relational aggression within a peer group has primarily been on outcomes of victimization that affect children's future relationships, such as 
victims experiencing social anxiety that negatively affects their ability to make new friendships. However, one area of research understudied is the relational aggression girls may experience from multiple peers. Despite the numerous studies examining relational aggression from a single friend, relational aggression from two or more peers either individually or from multiple peers teaming up has not been thoroughly examined. There is, therefore, a need to examine relationally aggressive bullies and victims as they exist in dyadic relationships, as well as within larger friendship networks and peer groups. Further, as self-disclosure takes place not only between two girls, but also between multiple girls, and there is risk that what one shares with another may be shared with others, there is a need to not only examine the overall relationship, but to closely look at how self-disclosure is related to girls' experiences with relational aggression.

When assessing children's experiences with overall aggression, there is support that children's experiences are related to how many friends they have. Wang et al. (2009) reported that adolescents who have more friends are more likely to engage in higher levels of bullying but are less likely to experience victimization. The authors asked students to identify how many friends they have (from 0 to 3 or more) and answer questions about their experiences with bullying and victimization. Due to the number of students who identified themselves as having 3 or more friends, the researchers collapsed this measure and looked at students who had fewer than three friends compared to those who had three or more friends. However, it is unclear if these friendships were individual dyadic relationships or if the friends of one child were also friends themselves. That is, it is unclear if each participant reported on single friendships or if they were reporting on friendship networks in which they are included. As such, it is possible that having larger friendship networks or peer groups could be associated with increased bullying and lower levels of victimization, but more support is needed to understand fully what 
is occurring between groups of children and adolescents and whether this pattern is found with children's experiences of relational aggression.

\section{Self-Disclosure}

\section{Definition}

Self-disclosure is sharing information about the self with someone else. More specifically, self-disclosure is verbally sharing private information about the self, personal experiences, feelings, emotions, desires, and thoughts; that is, information that is not readily obvious to others (Derlega, Metts, Petronio, \& Marqulis, 1993). Disclosure is not just a single action but is a process of sharing part of the self with others. However, there is disagreement about how to classify disclosure within research. For example, Grotpeter and Crick (1996) define self-disclosure as intimate exchange between friends, but disclosure can also be defined as a behavior that can increase intimacy within friendship while also serving other purposes (Derlega \& Grzelak, 1979). Further, different instances of disclosure are not treated equally. For example, Altman and Taylor (1973) separated types of disclosure into three levels, each characterized by increasingly personal information, whereas others have separated disclosure into descriptive and evaluative disclosure, as well as spontaneous disclosure and disclosure in response to a question (Joinson, 2001). Antaki, Barnes, and Leudar (2005) also proposed that instances of disclosure cannot be determined without knowing the context in which they occur. Despite these numerous approaches, the classification of disclosure typically comes down to three areas: the amount (frequency) of disclosure, the depth (emotional intensity) of the disclosure, and time spent disclosing (Cozby, 1973). Generally, individuals disclose less about highly emotionally intense information and more about superficial information.

The distinction between frequency and depth are important not only because they contribute to a different understanding of what disclosure is, but also because the 
conceptualization of disclosure has been shown to affect outcomes differently. For example, Collins and Miller (1994) reported studies that manipulated the depth of disclosure and found stronger liking effects for deeper levels of disclosure than those that manipulated the breadth of disclosure. Generally, though, it appears that, regardless of how disclosure is conceptualized, it is the content rather than the quantity of disclosure that contributes to liking and friendship development (Collins \& Miller, 2004). In other words, a relatively low amount of highly intense disclosure (e.g., sharing personal beliefs and needs) is a stronger predictor of outcomes than is a large amount of superficial disclosure.

When addressing self-disclosure, it is also interesting to acknowledge the potential for lying. DePaulo, Kashy, Kirkendol, Wyer, and Epstein (1996) supported the idea that lying is an everyday occurrence and that people lie about how they feel and what they are like. They stated lies can be described based on the content, reason, type, and referent of the lie. Content of lies refers to what is being lied about, including feelings, achievements, plans, and facts. With regard to the reason for lying, two reasons were identified: self-oriented lying and other-oriented lying. Both types were determined to be for either psychological reasons (i.e., avoid embarrassment, protect privacy, regulate feelings) or for personal gain (i.e., to make things easier, to avoid punishment, to avoid undesired tasks). Lies were also separated by type of lie, including outright lies (i.e., completely false statements), exaggerated lies (i.e., overstating a fact), and subtle lies (i.e., omitting detail). With regard to the referent, lies were told about the liar, about the partner in the interaction, about others not in the interaction, and about other events or objects. Interestingly, lies told to bother or annoy others were not included in this and subsequent studies (DePaulo \& Kashy, 1998; Kashy \& DePaulo, 1996) due to the low frequency of these lies (only between $1-2.5 \%$ of all lies). 
Based on these categories, DePaulo et al. (1996) found that people lie to others between $30-38 \%$ of the time with three out of four lies being self-oriented and the fourth being other-oriented, often to protect the feelings of others. They also found that people did not typically plan their lies and expected to be believed; however, these instances were less intimate and less pleasant for the liar. Further, Kashy and DePaulo (1996) found that people who tell more lies care more about the self-management and the impression they have on others. They are also more likely to manipulate others, but are often smooth when doing so, appearing sociable and likeable. However, those who told fewer lies were more likely to have higher quality same-sex relationships and greater socialization. Similarly, DePaulo and Kashy (1998) showed that people told fewer lies to those they felt the closest toward and felt more discomfort when lying to those with whom they felt the closest.

\section{Measuring Self-Disclosure}

As there are many definitions of self-disclosure, there are also many ways to measure self-disclosure. For example, Grotpeter and Crick (1996) included intimacy subscales in the FQM that measure the respondent's disclosure to her friend as well as her friend's disclosure to her. These subscales assess how often the respondent feels she can share information regarding her secrets, her problems, and things that make her sad, as well as her perception of how often her friend can share this same information. This approach focuses on frequency of disclosure. However, one of the most influential measures of disclosure, both in use and in influencing the development of later scales, focuses on the depth of disclosure. Jourard's Self-Disclosure Questionnaire (JSDQ, Jourard \& Lasakow, 1958) measures the depth of an individual's disclosure (no disclosure, general disclosure, full disclosure) of six content areas, including attitudes and opinions, tastes and interests, work, money, personality, and body. This measure has been used as the basis for many other self-disclosure scales, including Miller, Berg, and Archer's (1983) 
Self-Disclosure Index. Additionally, Snell, Miller, and Belk (1988) developed a scale that measures willingness to share information about eight specific feelings (i.e., anger, anxiety, apathy, calmness, depression, fear, happiness, and jealousy). This measure also focuses on the depth of disclosure. However, of these measures, only the FQM has been widely used with research involving children.

\section{Outcomes of Disclosure}

Research has identified both positive and negative outcomes related to self-disclosure. The potential emotional benefits of disclosing include higher esteem, more motivational support, social validation, a sense of connectedness, and greater self-awareness, whereas not disclosing has been linked to physical and emotional problems, obsessive thoughts, anxiety, and shame (Derlega et al., 1993; Ichiyama et al., 1993). Disclosing also allows the discloser to avoid creating hyperaccessible secrets and to receive new insight into problems (Kelly \& McKillop, 1996). However, these benefits are dependent on the response of the confidant. For example, Lepore, Ragan, and Jones (2000) showed participants an emotionally intense video and then assigned them to one of four disclosure groups: a no-talk group, a talk-only group, a validatingconfederate group, and an invalidating-confederate group. The authors found that those in the validation group, who had their feelings validated by a confederate, had fewer intrusive thoughts and less stress upon subsequent exposure to emotionally intense stimuli than did those in the no-talk group and talk-only group. Further, the benefits of talking were diminished for those in the invalidating group, who had their disclosure invalidated by a confederate.

Self-disclosure has also been associated with friendship development. Building a relationship is a dynamic process (Adams \& Blieszner, 1994), and self-disclosure is a vital part of both the initiation and maintenance phases of relationships, but different types of disclosure are typically present in each phase. The initiation phase of friendship is characterized by disclosure 
of superficial likes and similarities, whereas the maintenance phase is characterized by more intense and emotional self-disclosure (Buhrmester \& Prager, 1995). Although the initiation stage develops into the maintenance stage in part due to self-disclosure and the sharing of personal information, a high number of "me statements" is negatively associated with friendship development (Gottman, 1983). This indicates that from the initial meeting, children must control their behaviors and balance how much they talk about themselves with how much they disclose when directly asked by a peer. That is, friendship development is supported when children request disclosure from each other while monitoring their own unprompted selfstatements.

Social penetration theory (Altman \& Taylor, 1973) states that disclosure increases in both amount and breadth as friendships develop and become more intimate, and emotional self-disclosure is a stronger predictor of intimacy than factual disclosure (Laurenceau, Barrett, \& Pietromonaco, 1998). This documented difference in disclosure as friendships develop is one potential reason as to why relationship intimacy is often measured through disclosure in the relationship (e.g., see the FQM; Grotpeter \& Crick, 1996). Ayers (1979) further explained that new acquaintances share primarily descriptive information (statements about what something or someone is or is like), whereas those in a friendship shared evaluative information (judgment statements). Interestingly, when one member of a new acquaintance dyad shared evaluative information, the response to the information remained at a descriptive level. However, increased disclosure early in a friendship may accelerate the development of the friendship when it is reciprocated (Altman \& Taylor, 1973), and an initial evaluation that someone fits one's schema for what is believed to be a friend is associated with more intimate disclosure earlier in the relationships (Berg \& Clark, 1986). This pattern indicates that social expectations for 
disclosure and individual differences in levels of disclosure also influence the effect disclosure has on building friendships, especially in the early phase of development.

It is important to note that the majority of research on the relation between selfdisclosure and the development of friendships has focused on adult friendships. Although the disclosure of adolescents appears to be similar to that of adults, the specific processes may be different in childhood. For example, Rotenberg and Mann (1986) proposed that the role of selfdisclosure in friendship development is dependent on the age of the child. The authors presented kindergarten through sixth grade students with dyadic interactions that differed in the level of intimate disclosure from one child and the level of intimate response from a second child and asked students to report their likeability of and desire for friendship for the second child. They found that for sixth grade students only, respondents were rated as more likeable, and there was a higher desire for friendship, when the second child's response matched the first child's level of disclosure. In contrast, young children had higher desire for friendship ratings and rated the respondent as more likeable when the respondent had a low level of intimacy, regardless of whether the initial disclosure had a high or low level of intimacy, suggesting that disclosure is a more important indicator of children's relationships starting around early adolescence. Rotenberg and Mann (1986) concluded that the norm of reciprocity seen in adult relationships develops in children around early adolescence and only then contributes to children's likeability of peers.

One possible explanation for this pattern of findings is that adolescents value different social behaviors in friendships than they did in childhood, and those who violate these values are not as accepted by their peers as those who fit social norms. Support for this idea comes from Buhrmester and Prager (1995) who conducted a meta-analysis examining the amount of information shared with peers and the emotional intensity of that disclosure throughout 
development. They found that both the amount of self-disclosure to friends and the emotional intensity of that disclosure increased as children reached adolescence. Furthermore, these increases were larger for girls than they were for boys. This pattern shows that adolescents place more value in disclosure and view it as more typical and acceptable than they did when they were younger.

Despite the many benefits of self-disclosure, self-disclosure can also potentially result in negative outcomes for the discloser. Uneven or unbalanced levels of self-disclosure may affect the equality in the relationship and lead to changes in the behavior of the confidant as well as the relationship overall (Derlega et al., 1993). Disclosure can also blur personal boundaries resulting in loss of independence and an increase in vulnerability (Kelly \& McKillop, 1996). Furthermore, distress disclosure, a type of disclosure in which the discloser seeks out social support when sharing emotionally distressing information, can also result in the loss of support if the confidant is unable to handle the emotional content of the disclosure (Coates $\&$ Winston, 1987). This outcome is especially likely when the disclosure violates social norms (e.g., criminal activity), is highly emotional (e.g., terminal illness), or occurs at an inappropriate time (e.g., too early in a relationship; Derlega et al., 1993). When sharing information with others there is also a risk that a third party may find out. For example, Christophe and Rime (1997) showed that 66$78 \%$ of emotional disclosures were shared with others by the confidant. Further, more highly emotional disclosure was likely to be shared with more people by the confidant. Thus, disclosure may provide others with information that can be used to manipulate, control, or harm a relationship.

\section{Association Between Relational Aggression and Self-Disclosure}

The association between self-disclosure and relational aggression is particularly interesting; self-disclosure helps to build relationships, but relationally aggressive children may 
use this information to harm the relationship. Grotpeter and Crick (1996) showed that relationally aggressive girls (as nominated by their peer group) reported having friendships characterized by high levels of intimacy (defined as self-disclosure) received from their best friends. The relationally aggressive girls also reported a lower level of self-disclosure than their friend in a dyadic relationship. Murray-Close et al. (2007) reported similar findings. Using the procedure outlined by Grotpeter and Crick (1996), Murray-Close et al. (2007) assessed children's experiences with relational aggression and disclosure to their best friend at three time points over a one-year time period (Fall of fourth grade to Fall of fifth grade). The authors stated that increases in intimate disclosure by a close friend were associated with increases in relational aggression between best friends for girls. In other words, for girls, an increase in friendship intimacy is related to time-dependent increases in relational aggression (Murray-Close et al., 2007). Together, these results have led researchers such as Grotpeter and Crick to conclude that disclosure is not always a beneficial aspect of friendships as it is also associated with negative outcomes.

When interpreting these results, though, it is important to acknowledge that the friends of relationally aggressive girls are not necessarily the victims of relational aggression, as has been assumed in previous research. It is easy to imagine a case where a girl has a mutually supportive friendship with another girl that is characterized by high levels of self-disclosure but that same girl is relationally aggressive toward other girls in the class. Further, despite finding high levels of exclusivity (a negative friendship trait) among relationally aggressive girls, Grotpeter and Crick (1996) did not find lower levels of positive friendship qualities, such as validation, caring, companionship, and recreation, in the dyadic friendships of relationally aggressive girls. However, Bukowski et al. (1994) stated that conflict within a relationship is the quality most strongly associated with less security in the relationship. Given that security is 
highly correlated with closeness and help (Bukowski et al., 1994), it is logical that friendships high in conflict would be low in closeness and help, but this is the opposite of what Grotpeter and Crick reported. Although conflict and relational aggression are not identical constructs (e.g., Bukowski et al.'s conflict subscale primarily measures arguments whereas Grotpeter and Crick's relational-aggression-towards-others subscale measures teasing and ignoring others), they both assess negative interactions children have within their friendship and would logically be negatively associated with positive aspects of friendship.

Given the above research, it would seem that relationally aggressive girls may elicit high levels of self-disclosure from their friends. Does this mean that girls who engage in high levels of self-disclosure are at risk for being victims of relational aggression? Specifically, does providing personal information to relationally aggressive girls provide ammunition that could then be used against the discloser? To address this issue, Jones et al. (2011) used a modified version of the FQM (Grotpeter \& Crick, 1996) that assessed children's friends in general rather than a single dyadic friendship (i.e., "my friends and I" compared to the original "my friend and I"). This was accomplished by having children read items that asked about their experiences with the friends, including how often they share secrets and private information with their friends and how their friends treat them. Results showed that girls who experienced the most relational aggression (i.e., who reported being victims of relational aggression from their friends) disclosed less to their friends than did girls who did not experience relational aggression. This pattern is consistent with the idea that disclosure is used to form relationships and that relationships high in conflict and negative experiences are low in positive friendship qualities like disclosure. However, these results cannot be compared with past studies without accounting for potential differences due to the focus on a peer group as compared to a dyadic friendship as this difference may also influence results. This difference has not been examined empirically within 
the same study, and therefore research needs to examine the important distinction between single dyadic friendship and larger peer groups.

It is also important to acknowledge the potential influence of an informant mismatch that is present in previous research. Table 1 shows the possible informants (dyadic friendship, friendship network, peer group) for the behavior of the respondent and the behavior of others. A mismatch in the informant occurs when the informant for one variable, for example relational aggression, is different than the informant for a second variable that is possibly associated with the first variable, such as self-disclosure. For example, in Grotpeter and Crick's (1996) landmark study, measures of intimacy and self-disclosure were based on mutual friends completing reports on their friendship, whereas measures of relational aggression were based on peer nominations from the entire class. Within Table 1, this is depicted as A3 for relational aggression and B1 for self-disclosure. Thus, although Grotpeter and Crick (1996) showed that relationally aggressive girls are confidants for their friends, they did not report the level of aggression the relationally aggressive girl directed toward that same friend, making it unclear whether the friend was a victim. A similar methodological approach was employed by Murray-Close et al. (2007). These researchers measured relational aggression using peer nominations, but selfdisclosure was measured using participants' self-reports of their best-friend's behavior. Jones et al (2011) attempted to clarify the association between relational aggression and self-disclosure by addressing this mismatch in informant by focusing on self-reports of children's experiences with disclosure to their peers and aggression from those peers. Within Table 1, their approach is depicted as B3 for relational aggression and A3 for self-disclosure. This informant consistency allows for an alternative view of how relational aggression and disclosure are associated. However, Jones et al (2011) did not measure the experiences of children within a dyadic 
friendship. Therefore, there is still a clear need to address the inconsistency between informants further to understand the association between relational aggression and self-disclosure.

Table 1

Association Between Behavior and Type of Relationship Being Assessed Focus of Behavior
Type of Relationship
A. Respondent's
B. Other's behavior

behavior

\begin{tabular}{|c|c|c|}
\hline 1. Dyadic Friendship & A1 & B1 \\
\hline 2. Friendship Network & $\mathrm{A} 2$ & B2 \\
\hline 3. Peer Group & A3 & B3 \\
\hline
\end{tabular}

Additionally, it is important to consider that previous research has focused almost solely on the perspective of the aggressor and not on the victim of relational aggression. For example, Grotpeter and Crick (1996) identified bullies through peer nominations and then analyzed data from the bullies' self-reports but did not present results obtained from victims. This exclusive focus on the bully is potentially problematic for a number of reasons. One potential shortcoming is that aggressors and victims may have different experiences with disclosing. For example, although Grotpeter and Crick (1996) reported that relationally aggressive girls had lower levels of disclosure than their targets, their conclusions are based on the self-report data of the aggressors and not on a comparison of reported experiences for both the aggressor and the target. While it is important to understand how one perceives others' level of disclosure, as this is important to understanding how one views the relationship, it is also important to understand 
each person's experience with disclosure. Only the discloser is able to accurately assess how much she discloses compared to how much she withholds. It is possible that two people in a dyadic relationship may have different experiences with both their own and the other person's self-disclosure, and this discrepancy may contribute to their assessment of the relationship overall. Therefore, an examination of the association between self-disclosure and relational aggression should focus on the perspective of both the victim and the bully within both a dyadic friendship and their peer group to address these potential problems.

\section{Summary}

To summarize, given the potentially devastating outcomes associated with relational aggression, a better understanding of relational aggression is vital. A main focus of previous research on relational aggression has been to examine friendships of relationally aggressive girls, including self-disclosure between victims and bullies. However, there are inconsistent results depending on how self-disclosure is measured and whether the focus is on a single dyadic relationship or a friendship network (see Cillessen, Jiang, West, \& Laszkowski, 2005; Grotpeter \& Crick, 1996). Overall, there is agreement that understanding children's selfdisclosure is important in understanding relationally aggressive friendships, but the exact relation between these variables is unclear. Additional research is needed to understand these potential associations fully.

\section{Purpose and Hypotheses}

The purpose of this study was to expand on the previous research assessing the association between children's self-disclosure and their experiences with relational aggression. First, this study built on previous research by examining the experiences of both victims and bullies. Second, this study addressed children's experiences in a dyadic relationship, within their friendship network, and within the broader peer group. This study also aimed to replicate the 
findings reported by Grotpeter and Crick (1996) by examining what I perceive to be a mismatch of relationship contexts, namely, disclosure within a dyadic relationship by the friends of girls identified as a bully within their peer group. As relational aggression is more frequently experienced by girls than boys (Wang et al., 2009), is more hurtful for girls than boys (Rose \& Rudolph, 2006), and is viewed more negatively by girls than it is boys (Galen \& Underwood, 1997), this study focused only on the friendships and experiences of girls.

I hypothesized that the association between relational aggression and self-disclosure would depend on the relationship context being examined. Based on previous research with dyadic friendships (Grotpeter \& Crick, 1997; Murray-Close et al., 2007), I hypothesized that for dyadic friendships relational aggression victimization would be positively associated with disclosing information but negatively associated with being the confidant. Likewise, I hypothesized that relational aggressive bullying would be negatively associated with disclosing and positively associated with being a confidant (see Table 2). That is, I expected that victims would be more likely to disclose and less likely to be the confidant, whereas bullies would be less likely to disclose and more likely to be the confidant in relationally aggressive dyadic friendships. Given that friendships of relationally aggressive girls are similar to those of nonrelationally aggressive girls on many positive friendship qualities (Grotpeter \& Crick, 1996), I expected that disclosure would occur between friends, but bullies would withhold disclosure whereas victims would attempt to use disclosure to build the relationship. 
Table 2

Hypothesized Associations Between Relational Aggression and Self-Disclosure in Dyadic Friendships

\begin{tabular}{llc}
\hline & Victim & Bully \\
\hline Disclosing to Best Friend & Positive & Negative \\
Being a Confidant & Negative & Positive \\
\hline
\end{tabular}

This pattern was not expected for friendship networks and peer groups, although I hypothesized that the association between self-disclosure and relational aggression would be the same for friendship networks and peer groups. Unlike girls who are identified as a bully or a victim within a dyadic friendship who have many positive friendship characteristics, I expected that girls identified as either a bully or a victim by multiple peers would have poorer peer relationships. Given that conflict and aggression are associated with less prosocial behavior and lower friendship quality (Bukowski et al., 1994), and findings from Jones et al. (2010) showing those who experience the most aggression from their friends disclose the least, I expected group-identified bullies and victims would experience more negative friendship characteristics and would engage in less disclosure and be less of a confidant. For these types of relationship contexts I hypothesized that both relational aggression victimization and bullying would be negatively associated with both disclosing to others and being the confidant (Table 3). 
Table 3

Hypothesized Associations Between Relational Aggression and Self-Disclosure in Friendship Networks and Peer Groups

\begin{tabular}{lll}
\hline & Victim & Bully \\
\hline Disclosing to Others & Negative & Negative \\
Being a Confidant & Negative & Negative \\
\hline
\end{tabular}


CHAPTER III

METHOD

\section{Participants}

Participants were recruited from two organizations: a local community-based social organization (the community sample) and a local high school (the school sample). The community-based social organization was a single, large, activity-based organization focused on volunteerism, leadership, and skill building. The organization was comprised of multiple smaller groups that held weekly meetings throughout the year. For the community sample, the organization was contacted to obtain permission to contact group leaders and parents. Parents provided consent and girls provided assent prior to beginning the study. A total of 62 girls from seven groups within the community organization participated in the survey. Of the seven groups that participated, $100 \%$ of girls received consent to participate and approximately $95 \%$ of girls participated (two girls were absent during data collection and one girl chose not to participate as she was new to the group). Participants ranged in age from 7 years to 15 years of age with a mean age of $10.03(S D=2.10)$ years old. Participants were in first through ninth grades.

For the school sample, a rural high school was contacted to obtain approval from the school board to contact parents. Once approved, parents provided consent and girls provided assent prior to beginning the study. A total of 37 girls from the school received consent to participate in the survey and provided assent (approximately $18 \%$ participation rate). Participants in the school sample were older than those in the community sample and 
represented a different age group, ranging in age from 14 to 18 years old with a mean age of 15.89 years old $(S D=1.22)$. Participants were in ninth through twelfth grades.

\section{Measures of Victimization, Bullying, and Self-Disclosure}

\section{Friendship Networks}

To assess disclosure and relational aggression in a friendship network ( $\mathrm{A} 2$ and $\mathrm{B} 2$ in Table 4), both the community sample and school sample participants completed the Friendship Qualities Measure for a total of five friends who were also completing the survey. The FQM is a self-report scale developed to measure 14 qualities of children's friendship, including victimization, bullying, and self-disclosure, as well as overall friendship satisfaction. Of the 14 qualities assessed by the FQM, four qualities were of interest in the study. The first quality of interest was a measure of intimate exchange (Intimate Exchange I), or self-disclosure, from the participant to her friend. This assessed how much each participant tells her friend about secrets and other private information (i.e., disclosure). The second quality was a measure of being a confidant (Intimate Exchange II), or intimate exchange from the participant's friend to the participant, to measure how much each participant's friend shares secrets and other private information with the participant (i.e., being a confidant). The third quality was a measure of victimization (Relational Aggression Toward Friends), which measured how much each participant is ignored or left out by her friend, or how much her secrets are shared by her friend (i.e., victimization). The last quality of interest was a measure of bullying. In place of the Relational Aggression Toward Others subscale included on the FQM that measures bullying a girl may engage in with her friend toward others outside the dyad, a modified version of the Relational Aggression Toward Friends subscale was used. To measure bullying within the dyad, items were modified to measure how much each participant ignores or leaves out her friend, or shares her friend's secrets with others. The relational aggression subscales each contain four 
items, whereas the intimate exchange to friends and intimate exchange from friends subscales contain three items each. Each item requires the participant to report on her friendship with a single friend and uses a 5-point Likert scale with $1=$ not at all true and $5=$ always true. To assess participants' experiences within their friendship network, item ratings were summed and then averaged across friends to determine girls' average disclosure to their friendship network, disclosure from peers in their friendship network, relational aggression victimization within their friendship network, and relational aggression bullying within their friendship network.

Table 4

Measures Used for Behaviors Based on Type of Relationship Being Assessed

Focus of Behavior
Type of Relationship
A. Respondent's behavior
B. Other's behavior

1. Dyadic Friendship

Self-report and Friend

Self-report and Friend

Report

Report

2. Friendship Network

Self-report

Self-report

3. Peer Group

Peer Nomination

Peer Nomination

\section{Dyadic Friendships}

To assess each participant's disclosure to and from their best friend (A1 in Table 4), as well as victimization from and aggression toward their best friend, each participant completed the FQM on their self-identified best friend (from among the participants in the study), with their friend also reporting on them. For each dyad, each participant reported on her highest 
ranked friendship that was reciprocated by another girl in her group. This approach is described in further detail in data analysis. Additionally, the reports from each participant's friend (B1 in Table 4) provided a second measure of each participant's behavior in their dyadic friendship.

\section{Peer Groups}

To assess behavior in the broader peer group ( $\mathrm{A} 3$ and $\mathrm{B} 3$ in Table 4), participants completed a peer nomination form. Peer nominations are a commonly used approach to assessing children's social adjustment, behaviors, and popularity in schools (Grotpeter \& Crick, 1996; Murray-Close et al., 2007). The peer nomination scale contained five items with one item each for relational aggression victimization, relational aggression bullying, self-disclosure to others, receiving self-disclosure from others, and general friendliness toward others (Appendix A). The relational aggression bullying, relational aggression victimization, self-disclosure to others, and receiving self-disclosure from others subscales were developed for this study based on items included in the FQM. The general-friendliness item was included as a practice item to acclimate girls to the survey and the peer nomination form. Consistent with previous research using peer nominations (i.e., Grotpeter \& Crick, 1996), community-sample participants were provided with a list of all participating girls from their group, and school-sample participants were provided with a list of all participating girls from their school. Both groups were asked to nominate up to three girls for each item. Each student's score on a given item was the number of nominations received across all participants.

\section{Procedure}

\section{Community Sample}

For the community sample, a local community-based social organization was contacted, and meetings were held with group leaders regarding the purpose of the study. Group leaders who were interested in the study then contacted the researcher. Group leaders were asked to 
distribute and collect consent forms from parents (Appendix B). The consent form defined what relational aggression is and then described that participants would complete a survey about their experiences with prosocial behavior and relational aggression, including both victimization and bullying, within their friendships. The consent form also described that participants would complete questions about their disclosure to their friends. Parents were provided with contact information for the researchers to allow parents to contact researchers with questions or concerns. Girls who returned a consent form, regardless of whether they received consent to complete the study, were entered into a drawing to win a gift card. Girls also signed an assent form (Appendix C). All data were confidential. Participants were given a unique ID number that was linked to their data and only accessible to the researcher. ID numbers were assigned during the session.

Girls with both parental consent and assent participated in one session. Participants first completed a paper-and-pencil peer nomination to nominate girls in their group who show high levels of relational aggression bullying or victimization, as well as girls who show high levels of self-disclosure to others or are the confidant for other girls. Participants also completed a paperand-pencil version of the abbreviated FQM. Girls were asked to complete one FQM for each of five friends who were also in their group. Girls first completed the FQM items for their first best friend followed by their second, third, fourth, and fifth best friend in their group. The survey took approximately 30-40 minutes and was administered in a group format. Each participating group from the community organization completed the survey separately, with groups ranging in size from six to ten participants. Following completion of the study, participants received a debriefing form (Appendix D) that explained the purpose of the study and included the contact information for the researcher. Participants who had further questions or concerns were asked 
to contact the researcher. The form also included the contact information for the Illinois State University's Research Ethics and Compliance Office.

\section{School Sample}

School administrators at a rural high school were contacted and provided with information regarding the purpose of the study. School administrators sought approval from the school board. Once approved, consent forms were sent home with all students. As with the community sample, the consent form provided a definition of relational aggression and described that participants would complete a survey about their experiences with prosocial behavior and relational aggression, including both victimization and bullying, within their friendships. The consent form also described that participants would complete questions about their disclosure to their friends. Parents were provided with contact information for the researchers to allow parents to contact researchers with questions or concerns. Students were asked to return the consent forms to their guidance counselor. As with the community sample, students who returned a consent form (Appendix E), regardless of whether they received consent to complete the study, were entered into a drawing to win a gift card. Students who received consent from their parent also signed an assent form (Appendix F) prior to starting the study. All data were confidential. Participants were given a unique ID number that was linked to their data and only accessible to the researchers. ID numbers were assigned during the session.

The survey took approximately 30 minutes and was administered in a large group format (i.e., all participants at the same time) during a study hall period at the school. Schoolsample participants completed the same paper-and-pencil peer-nomination and FQM measures described for the community sample. Following completion of the study, participants received a debriefing form that was similar to that provided to the community sample (Appendix G). 
CHAPTER IV

\section{ANALYSIS OF THE DATA}

\section{Overview of Data Analyses}

In this chapter, I present the results of analyses of dyadic friendships, followed by friendship networks, and finally peer groups. For each, I begin with analyses for the community sample and then the school sample. Although specific hypotheses were only made for four correlations, including being a victim and disclosing, being a victim and being a confidant, being an aggressor and disclosing, and being an aggressor and being a confidant, correlations between being an aggressor and being a victim, and disclosing to others and being a confidant were also examined for each friendship type. For dyadic friendships, self-reports and peer-reports were analyzed using a multitrait-multimethod approach. For friendship networks, participants' reports for all friends were averaged first for each friend and then for all friends to develop a single grand-mean for being an aggressor, being a victim, disclosing to others, and being a confidant. The peer-group analyses were conducted using a peer nomination form, on which participants received one point each time they were nominated for each variable. These scores were then used to examine correlations between the four variables.

\section{Dyadic Friendships}

To analyze data from best-friend dyadic relationships, experiences with relational aggression and self-disclosure were addressed through a multitrait-multimethod approach (Campbell \& Fiske, 1959). In this approach, peer and self-reports are considered different 
methods, and relational aggression bullying, relational aggression victimization, disclosure to others, and being the confidant for others' disclosure are considered different traits.

For each dyad, each participant reported on her highest ranked friendship that was reciprocated by another girl in her group. For example, if Cierra reported her best friend was Laura and Laura also identified Cierra as a friend at any position in her own ranking, then Cierra would be paired with Laura. However, if Laura did not reciprocate the friendship and did not report on Cierra, then Cierra's second choice, Abigail, would be looked at and used if Abigail also reported on Cierra. Additionally, if Cierra is matched with Laura, Laura could be matched with a different friend, other than Cierra, if Laura ranked another girl in a higher position. This approach maximized the number of participants used in the analysis and the number of participants reporting on their first-choice best friend.

Following this approach, $90 \%$ of community-sample participants were included in data analyses for friendship dyads. One participant was excluded because she did not report on girls in her group, and two participants were excluded because their ranked friends did not reciprocate the friendship. Of the 58 participants included in this portion of data analysis, 51 reported on their first choice best friend, three reported on their second choice, one reported on her third choice, one reported on her fourth choice, and two reported on their fifth choice. For the school sample, $92 \%$ of participants were included in data analyses for friendship dyads. Two participants were excluded because their ranked friends did not reciprocate the friendship, and one participant was excluded because she did not report on girls in her school. Of the 34 participants, 30 reported on their first-choice best friend, three reported on their second choice, and one reported on her fifth choice.

Means and standard deviations for self-reports and peer-reports for aggression, victimization, disclosing, and being a confidant for both the community and school samples are 
presented in Table 5. Recall that participants in the community sample were in a different age group than those in the school sample, with those in the community sample representing middle childhood through preadolescence and those in the school sample representing adolescence. As the table indicates, the community sample had significantly higher self-reports of victimization and significantly lower self-reports of being a confidant than the school sample. The community sample also had significantly lower peer-reports of disclosure and being a confidant than the school sample.

Table 5

Means and Standard Deviations for Self-Reports and Peer-Reports for Community and School Samples

\begin{tabular}{|c|c|c|c|c|c|c|}
\hline & \multicolumn{2}{|c|}{ Community Sample $(n=58)$} & \multicolumn{2}{|c|}{ School Sample $(n=34)$} & \multirow[b]{2}{*}{$t$} & \multirow[b]{2}{*}{$d$} \\
\hline & $M$ & $S D$ & $M$ & $S D$ & & \\
\hline \multicolumn{7}{|l|}{ Self-Report } \\
\hline Aggressor & 1.50 & .76 & 1.28 & .34 & 1.59 & .34 \\
\hline Victim & 1.67 & .82 & 1.31 & .38 & $2.41 *$ & .52 \\
\hline Disclosure & 4.01 & .95 & 4.39 & .90 & -1.89 & -.4 \\
\hline Confidant & 4.08 & 1.11 & 4.75 & .76 & $-3.11 *$ & -.7 \\
\hline \multicolumn{7}{|l|}{ Peer-Report } \\
\hline Aggressor & 1.46 & .66 & 1.24 & .31 & 1.83 & .39 \\
\hline Victim & 1.59 & .76 & 1.32 & .38 & 1.93 & .42 \\
\hline Disclosure & 3.98 & 1.03 & 4.45 & .73 & $-2.34 *$ & -.5 \\
\hline Confidant & 4.12 & 1.04 & 4.85 & .39 & $-3.93 *$ & -.8 \\
\hline
\end{tabular}


To test the hypotheses about the relation between relational aggression and disclosure, eight correlations were examined (see Table 6). The association between being victimized and disclosing to one's best friend was assessed by both self-report $\left(r_{\mathrm{B} 1 \mathrm{D} 1}\right)$ and peer-report $\left(r_{\mathrm{B} 2 \mathrm{D} 2}\right)$. Likewise, the association between being victimized by one's best friend and being a confidant for that friend (i.e., disclosure from one's best friend) was assessed by self-report $\left(r_{\mathrm{B} 1 \mathrm{C} 1}\right)$ and peer-report $\left(r_{\mathrm{B} 2 \mathrm{C} 2}\right)$. Associations between bullying one's best friend and disclosure to that friend were assessed by both self- $\left(r_{\mathrm{A} 1 \mathrm{D} 1}\right)$ and peer-report $\left(r_{\mathrm{A} 2 \mathrm{D} 2}\right)$, as were associations between bullying one's best friend and being a confidant for that friend $\left(r_{\mathrm{A} 1 \mathrm{C} 1}\right.$ and $\left.r_{\mathrm{A} 2 \mathrm{C} 2}\right)$. 
Table 6

Multitrait-Multimethod Analysis for Best-Friend Dyadic Friendships

\begin{tabular}{|c|c|c|c|c|c|c|c|c|c|}
\hline & & \multicolumn{4}{|c|}{ Self Report } & \multicolumn{4}{|c|}{ Peer Report } \\
\hline & & \multicolumn{2}{|c|}{$\begin{array}{l}\text { Relational } \\
\text { Aggression }\end{array}$} & \multicolumn{2}{|c|}{ Self-disclosure } & \multicolumn{2}{|c|}{$\begin{array}{l}\text { Relational } \\
\text { Aggression }\end{array}$} & \multicolumn{2}{|c|}{ Self-disclosure } \\
\hline & & $\mathrm{A} 1$ & B1 & C1 & D1 & $\mathrm{A} 2$ & B2 & $\mathrm{C} 2$ & D2 \\
\hline \multicolumn{10}{|l|}{ Self Report } \\
\hline Aggressor & $\mathrm{A} 1$ & -- & $.76^{*}$ & .09 & -.08 & .13 & .33 & .09 & .09 \\
\hline Victim & B1 & $.84^{* *}$ & -- & .16 & .11 & .26 & $.48^{* *}$ & .11 & .18 \\
\hline Confidant & $\mathrm{C} 1$ & -.09 & .01 & -- & $.72 * *$ & .13 & .18 & .25 & .02 \\
\hline Disclosure & D1 & -.02 & .07 & $.83^{* *}$ & -- & .18 & .03 & .06 & .31 \\
\hline \multicolumn{10}{|l|}{ Peer Report } \\
\hline Aggressor & $\mathrm{A} 2$ & .07 & $.27^{*}$ & .13 & .20 & -- & $.67 * *$ & -.09 & -.32 \\
\hline Victim & B2 & .16 & $.38^{* *}$ & .14 & .21 & $.78^{* *}$ & -- & .10 & -.22 \\
\hline Confidant & $\mathrm{C} 2$ & .18 & .14 & .16 & .12 & -.05 & -.12 & -- & .34 \\
\hline Disclosure & D2 & .19 & .22 & .14 & .03 & -.02 & -.06 & $.81 * *$ & -- \\
\hline
\end{tabular}

Note. Community sample $(n=58)$ data are presented in the lower left side of the table. School sample $(n=34)$ data are presented in the upper right side of the table.

${ }^{*} p<.05 .{ }^{*} p<.01$.

\section{Community Sample}

For the community sample (lower-left of Table 6), there was a significant correlation between self-reports of being an aggressor and self-reports of being a victim, $r=.84$, indicating that girls who identify as a bully also identify as a victim. There was also a significant correlation between self-reported disclosure and being a confidant, $r=.83$, indicating girls who disclose to their friend also report having their friend disclose to them. These correlations were also significant for peer reports, that is, there were significant correlations between peer-reported aggression and peer-reported victimization, $r=.78$, as well between peer-reported disclosure 
and being a confidant, $r=.81$. This indicates that girls who perceive their friend as aggressive also report their friend is a victim, and girls who have friends who disclose to them also report these girls are confidants. An examination of scatterplots revealed that all of these significant correlations appear to be due to a small number of girls who reported very high victimization and very high aggression, as well as a few girls who reported low levels of disclosure and low levels of being a confidant.

There were also significant correlations between self-reported victimization and peer reported aggression, $r=.27$, and between self-reported victimization and peer-reported victimization, $r=.38$. This former heteromethod correlation indicates the degree to which friends agree with each other; thus, it reflects the convergent validity of the measure of victimization (Campbell \& Fiske, 1959). These correlations therefore indicate that girls who identify as a victim have friends who believe they are both a bully and a victim. Interestingly, self-reports and peer-reports of aggression, disclosure, and being a confidant were not correlated. Thus, friends did not agree with each other on the level of aggression, disclosure, or being a confidant in the friendship.

Recall that I had hypothesized a positive correlation between victimization and disclosure but a negative correlation between victimization and being a confidant. I also hypothesized a negative association between aggression and disclosing but a positive correlation between aggression and being a confidant. Contrary to my hypotheses, there was no evidence of significant correlations between self-reported and peer-reported measures of (a) aggression or victimization and (b) disclosing or being a confidant. None of these correlations was stronger than $r=.20$. 


\section{School Sample}

For the school sample (upper-right of Table 6), there was a significant correlation between self-reported aggression and victimization, $r=.76$. This indicates girls who believe they are victims also identify as bullies. The correlation between peer-reported victimization and peer-reported aggression was also significant, $r=.67$, indicating girls who perceive their friends as bullies also identify their friends as victims. In addition, there was a significant correlation between self-reported disclosure and self-reports of being a confidant, $r=.72$, suggesting that girls who share personal information with their friend also are targets of disclosure from that friend. Although not statistically significant, there was a medium effect (i.e., a correlation near .30; Cohen, 1992) for the monomethod correlation between peer-reported disclosure and peerreports of being a confidant among the school sample, $r=.34$. As with the community sample, these significant correlations appear to be due to a few girls who reported very high victimization and very high aggression, as well as a few girls who reported low levels of disclosure and low levels of being a confidant.

In terms of heteromethod correlations (i.e., agreement between friends), there was a significant correlation between peer-reported victimization and self-reported victimization, $r=$ .48 , indicating girls who believe they are victimized also have friends who feel victimized. As with the community sample, there was no evidence that self-reports of aggression, disclosure, and being a confidant were associated with peer-reports of the same constructs.

To test the primary hypotheses, I examined the correlations between (a) aggression/victimization and (b) confidant/disclosure. As with the community sample, there was no evidence of significant correlations between self-reported or peer-reported measures of aggression/victimization and disclosing/being a confidant for the school sample. There was a medium effect for the correlation between peer-reported disclosure and aggression among the 
school sample, $r=-.32$, but this correlation was negative, not positive as predicted. Thus, the primary study hypotheses were not supported for dyadic friendships.

\section{Summary of Dyadic Friendships}

In regard to self-report only and peer-report only (i.e., monomethod correlations), correlations between self-reported aggression and victimization, self-reported disclosure and being a confidant, and peer-reported aggression and victimization were significant for both groups. The correlation between peer-reported disclosure and being a confidant was significant only for the community sample. In regard to self-report and peer-report correlations, the correlation between self-reported victimization and peer-reported victimization was significant for both groups, but the correlation between self-reported victimization and peer-reported aggression was only significant for the community sample.

\section{Friendship Networks}

To analyze friendship networks, data from the Relational Aggression Toward Others (bullying), Relational Aggression Toward Friends (victimization), Intimate Exchange I (selfdisclosure), and Intimate Exchange II (being a confidant) subscales of the FQM (Grotpeter \& Crick, 1996) were used. For each participant, ratings on each item for each of the subscales (three items each for Intimate Exchange I and Intimate Exchange II, and four items each for Relational Aggression Toward Friends and Relational Aggression Toward Others) were averaged separately for each friendship for which they reported (up to five different friend reports). Averaged subscale scores were then averaged again across all five friendships for each participant to produce a single grand-mean (averaged over items and friends) for each participant for each of the four variables. The means and standard deviations for each subscale for the community sample and school sample are presented in Table 7. As previously stated, recall that the community sample included participants from middle childhood through 
preadolescence and the school sample included adolescent participants. As the table indicates, the community sample had significantly higher reports of victimization and significantly lower reports of disclosure than the school sample.

Table 7

Means and Standard Deviations for Friendship Networks for Community and School Samples Community Sample $(n=60) \quad$ School Sample $(n=37)$

\begin{tabular}{|c|c|c|c|c|c|c|}
\hline Measure & $M$ & $S D$ & $M$ & $S D$ & $t$ & $d$ \\
\hline $\begin{array}{l}\text { Relational } \\
\text { Aggression } \\
\text { Bullying }\end{array}$ & 1.51 & .61 & 1.31 & .37 & 1.80 & .38 \\
\hline $\begin{array}{l}\text { Relational } \\
\text { Aggression } \\
\text { Victimization }\end{array}$ & 1.68 & .62 & 1.42 & .51 & $2.14 *$ & .45 \\
\hline $\begin{array}{l}\text { Self-Disclosure } \\
\text { to Others }\end{array}$ & 3.63 & .99 & 4.64 & .69 & $-5.44 *$ & -1 \\
\hline $\begin{array}{l}\text { Confidant to } \\
\text { Others }\end{array}$ & 3.88 & 1.05 & 4.18 & .75 & -1.51 & -.3 \\
\hline
\end{tabular}

For the friendship networks of the community sample participants, 56 girls ( $90 \%$ of participants) reported on five friendships, one girl reported on four friendships, one girl reported on three friendships, one girl reported on two friendships, one girl reported on one friendship, and two girls did not report on any friendships with girls in their group. For the school sample, 29 girls (78\% of participants) reported on five friendships, four girls reported on four friendships, three girls reported on two friendships, and one girl reported on one friendship. 
I hypothesized that both relational aggression victimization and bullying would be negatively associated with both disclosing to others and being the confidant. Correlation coefficients between victimization and disclosing, victimization and being a confidant, bullying and disclosing, and bullying and being a confidant were examined (Table 8).

\section{Community Sample}

For the community sample, the correlation between being an aggressor and being a victim was significant, indicating girls who bully are also bullied by members of their friendship network. Additionally, the correlation between disclosing to others and being a confidant was significant, indicating girls who share information with their friends also have friends who share information with them. There was also a significant correlation between disclosing to others and being a victim, indicating girls who share information with their friends are also bullied by members of their friendship network. Contrary to my other hypotheses, correlations between relational aggression victimization and being a confidant, relational aggression bullying and being a confidant, and relational aggression victimization and disclosing were not significant.

\section{School Sample}

As with the community sample, the correlation between being an aggressor and being a victim, and the correlation between disclosing to others and being a confidant, were significant for the school sample. This indicates girls who are bullies are also victims, and girls who share information with others have friends who share information with them. There was no evidence that correlations between relational aggression victimization and being a confidant, relational aggression victimization and disclosing, relational aggression bullying and being a confidant, and relational aggression victimization and disclosing were significant for the school sample. 
Table 8

Correlation Coefficients for Friendship Networks

\begin{tabular}{llllll}
\hline & & \multicolumn{2}{l}{ Relational Aggression } & \multicolumn{2}{c}{ Self-Disclosure } \\
\hline & & A1 & B1 & C1 & D1 \\
\hline Aggressor & A1 & - & $.91^{* *}$ & -.17 & -.16 \\
Victim & B1 & $.80^{* *}$ & - & -.07 & -.12 \\
Confidant & C1 & .01 & .20 & - & $.57^{* *}$ \\
Disclosure & D1 & .05 & $.26^{*}$ & $.85^{* *}$ & - \\
\hline
\end{tabular}

Note. Community sample $(N=60)$ data are presented in the lower left side of the table. School sample $(N=37)$ data are presented in the upper right side of the table.

${ }^{*} p<.05 .{ }^{* *} p<.01$.

\section{Peer Groups}

To analyze the peer group, data from the peer nomination form were used. Participants received 1 point for each nomination they received from girls in their group. Because the number of nominations a girl could receive was dependent on the number of girls providing nominations, for the community sample only, peer-nomination scores were standardized within groups. This was not done for the school sample, as all participants were part of a single group. The number of nominations received for relationally aggressive bullying, relationally aggressive victimization, self-disclosure to others, and being a confidant to others for the community sample are presented in Table 9 and for the school sample in Table 10. As indicated in the tables, for the community sample, most girls were identified by four or fewer participants as being a bully, a victim, someone who discloses to others, or someone who is a confidant for others. For the school sample, most girls were identified by three or fewer participants as being a bully, a victim, someone who discloses to others, or someone who is confidant for others. For the community sample, the maximum number of nominations received was seven for both 
bullying and victimization, with two girls receiving seven nominations for being a bully and one girl receiving seven nominations for being a victim. The maximum number of nominations for self-disclosure and being a confidant was six, with two girls receiving six nominations for each. For the school sample, the maximum number of nominations for victimization, self-disclosure, and being a confidant was six, with one girl receiving six nominations for each category. For bullying, one girl received ten nominations. The next highest number of nominations was six (one girl).

Table 9

Number of Nominations for Each Variable for Community Sample Participants

\begin{tabular}{lcccc}
\hline $\begin{array}{l}\text { Number of } \\
\text { Nominations }\end{array}$ & $\begin{array}{c}\text { Relational } \\
\text { Aggression Bully }\end{array}$ & $\begin{array}{c}\text { Relational } \\
\text { Aggression } \\
\text { Victim }\end{array}$ & $\begin{array}{c}\text { Self-Disclosure to } \\
\text { others }\end{array}$ & $\begin{array}{c}\text { Confidant to } \\
\text { others }\end{array}$ \\
\hline 0 & 12 & 6 & 5 & 3 \\
1 & 10 & 9 & 11 & 16 \\
2 & 10 & 21 & 12 & 10 \\
3 & 5 & 6 & 9 & 10 \\
4 & 6 & 1 & 7 & 4 \\
5 & 2 & 2 & 3 & 4 \\
6 & 2 & 3 & 2 & 2 \\
7 & 2 & 1 & 0 & 0 \\
Total & 49 & 49 & 49 & 49 \\
\hline
\end{tabular}


Table 10

Number of Nominations for Each Variable for School Sample Participants

\begin{tabular}{lcccc}
\hline Number of & \multicolumn{4}{c}{ Number of Girls } \\
Nominations & $\begin{array}{c}\text { Relational } \\
\text { Aggression Bully }\end{array}$ & $\begin{array}{c}\text { Relational } \\
\text { Aggression } \\
\text { Victim }\end{array}$ & $\begin{array}{c}\text { Self-Disclosure to } \\
\text { others }\end{array}$ & $\begin{array}{c}\text { Confidant to } \\
\text { others }\end{array}$ \\
0 & 13 & 13 & 7 & \\
1 & 10 & 8 & 14 & 7 \\
2 & 4 & 7 & 11 & 10 \\
3 & 4 & 4 & 3 & 7 \\
4 & 2 & 2 & 0 & 1 \\
5 & 1 & 1 & 0 & 1 \\
6 & 1 & 1 & 1 & 1 \\
7 & 0 & 0 & 0 & 0 \\
8 & 0 & 0 & 0 & 0 \\
9 & 0 & 0 & 0 & 0 \\
10 & 1 & 0 & 0 & 36 \\
Total & 36 & 36 & 36 & \\
\hline
\end{tabular}

As with the friendship network, I hypothesized that both relational aggression victimization and bullying would be negatively associated with both disclosing to others and being the confidant. Correlation coefficients between victimization and disclosing, victimization and being a confidant, bullying and disclosing, and bullying and being a confidant were examined. These are presented in Table 11.

\section{Community Sample}

For the community sample (lower-left of Table 11), there was a significant positive correlation between relational aggression bullying and disclosure to others. This finding suggests that those who are identified as a bully by the peer group are also seen as disclosing to others. No other correlations were significant for the community-sample peer-group data. 
Table 11

Correlation Coefficients for Peer Groups

\begin{tabular}{lcccc}
\hline & \multicolumn{2}{c}{ Relational Aggression } & \multicolumn{2}{c}{ Self-Disclosure } \\
\hline & Aggressor & Victim & Confidant & Disclosure \\
\hline Aggressor & - & .22 & -.16 & .12 \\
Victim & .16 & - & .11 & $.39 *$ \\
Confidant & -.07 & .05 & - & $.39 *$ \\
Disclosure & $.38^{* *}$ & .17 & .16 & - \\
\hline
\end{tabular}

Note. Community sample $(N=49)$ data are presented in the lower left side of the table. School sample $(N=36)$ data are presented in the upper right side of the table.

${ }^{*} p<.05 .{ }^{* *} p<.01$.

\section{School Sample}

For the school sample (upper-right of Table 11), there was a significant positive correlation between relational aggression victimization and disclosure and a significant positive correlation between disclosing and being a confidant. This finding indicates that girls who are perceived as being a victim are also seen as disclosing to others in the peer group, and girls who are seen as disclosing are also a confidant. There were no other significant correlations among the peer-group data for the school sample.

\section{Summary of Results}

Overall, being a bully was largely associated with being a victim for both dyadic friendships and friendship networks of the community and school samples, especially with monomethod reports of dyadic relationships. With heteromethod reports for dyadic friendships, self-reports of being a bully were only associated with peer reports of being a victim for the community sample. Being a bully was also not associated with being a victim within the peer group of either sample. Further, being a confidant was largely associated with disclosing for 
friendship networks of both samples and the dyadic friendships of those in the community sample. For the school sample, only self-reports of dyadic relationships showed this association. Additionally, being a confidant was associated with disclosing in the peer group only for the school sample. In general, there was little agreement between self-reports and peer-reports for dyadic relationships, but self-reports of victimization were associated with peer-reports of victimization. Of the initial hypotheses regarding self-disclosure and relational aggression, victimization was only associated with disclosing to the peer group of the school sample and the friendship network of the community sample. For the community sample peer group, disclosing was associated with being a bully. 


\section{CHAPTER V}

DISCUSSION

\section{Dyadic Friendships}

Earlier, I posed the questions, "Are girls who engage in high levels of self-disclosure at risk for being victims of relational aggression?" and "Does providing personal information to relationally aggressive girls provide ammunition that could be used against the discloser?" I expected that when examining the association between relational aggression and self-disclosure that the direction of the association would depend on the relationship context being examined. For dyadic friendships, I expected that girls who were victimized would be more likely to disclose to their best friend. Contrary to my hypothesis, and contrary to previous research showing girls who are victimized show high levels of disclosure to their best friend in a dyadic relationship (Grotpeter \& Crick, 1996), there was no evidence that this association was significant in the current study for either the community sample or the school sample for neither monomethod nor heteromethod reports. I also hypothesized that girls who were victimized would be less likely to be a confidant, as their best friend would withhold disclosure. This hypothesis was also not supported for either the community sample nor the school sample. One possible explanation for these findings is that the students included in this study were different ages than those included in previous studies. Both Grotpeter and Crick (1996) and Murray-Close et al. (2007) included elementary school students, and this study included a high-school sample. However, the community-sample participants were the same age as those in the previous study. 
As such, it is more likely that self-disclosure is treated differently by the girls in the groups being evaluated in the current study.

For example, although Grotpeter and Crick (1996) found that aggressive girls reported high levels of positive friendship qualities in their dyadic friendships, it is possible that prolonged aggression could weaken a relationship to the point that the importance of the relationship is diminished or the relationship is eventually completely dissolved, thus allowing a relationship with a more positive peer to be seen as the best friend. This possibility could mean that girls who engage in disclosure, but experience frequent aggression in return, could end this type of relationship in favor of one that provides more positive and prosocial support for disclosure. Friendships in Grotpeter and Crick's study were relatively new, whereas friendships in the current study had likely continued for much longer given the older age of the participants in the school sample and the possibility that many of the participants had been in school with each other or part of their community group organization for many years. Even friendships in MurrayClose et al.'s (2007) study were only followed over the course of one academic year and the beginning of the following semester. The friendships in the current study were likely in the maintenance phase, suggesting that girls had actively evaluated their relationship and chosen to maintain the relationship based on a number of qualities and experiences, whereas it is possible that previous studies assessed relationships in earlier stages of friendships. Further, although Grotpeter and Crick (1996) stated that girls who engaged in higher level of relational aggression had friendships characterized by similar levels of positive friendship qualities as did nonaggressive girls, others have shown that girls who have higher quality best-friendships experience less overall aggression from their best friend (Rubin et al., 2004). Therefore, it is possible that girls in this study identified best-friend relationships that were higher in positive friendship qualities and lower in negative qualities, such as aggression, as these positive 
relationships are typically more valuable and beneficial than those with high levels of conflict. These friendships would therefore be more likely to provide social support and emotional understanding, rather than aggression, for girls who disclose, and explain the discrepant findings of the current study.

The difference in results for this study is further supported by the fact that Grotpeter and Crick paired students into a single dyad based on their rankings, resulting in students rating friendships that were highly rated but not necessarily the top rated friendship. This study, however, matched participants to their top ranked reciprocated relationship, allowing each girl to report on her perceived best friend dyad without locking girls into a single friendship pair. It is possible that this process allowed the current study to look at girls' self-identified true best friend relationships, and therefore likely their most positive friendship, whereas previous studies have only looked at highly liked peers.

For dyadic relationships, I also hypothesized that relationally aggressive bullying would be negatively associated with disclosing and positively associated with being a confidant, and there was no evidence that either of these were supported in this study. Overall, combined with the findings regarding victimization and disclosure, this pattern suggests that experiences with bullying, as either a bully or a victim, are not consistently associated with experiences with disclosure, either disclosing to others or being a confidant. One explanation for this discrepant finding is, as mentioned previously, Grotpeter and Crick (1996) and Murray-Close et al. (2007) had students identify friendships only within their classroom, and this study allowed girls in the school sample to identify friendships with anyone in their school (the two above mentioned studies and the current study have only allowed nominations of girls who had received permission to be included in the study). Given the more controlled environment in an elementary class and the lower potential for developing a variety of friendships based on mutual 
interests, friends in the previous studies might have had more individual differences than similarities with their friends with regard to beliefs, hobbies, interests, etc., making the sharing of private information more valuable in terms of gaining power in the relationships. The school sample participants in the current study had more options to identify those girls with whom they had chosen to maintain friendship, regardless of class placement, increasing the likelihood that they chose to nominate friends who share similar interests and beliefs. Further, for the community sample participants, participation in the group suggests these girls may share many interests, hobbies, likes, and dislikes. For both the current school sample and community sample, it is possible that having more similarities with a friend makes the sharing of private information less valuable for relational aggression, as what one girl shares with another is possibly what the confidant would also share with her peer. Threatening to share a secret is not as helpful for establishing power and manipulating a relationship when the potential victim could share the same secret about the potential bully. It is possible that if the school sample had been limited to only those in their homeroom class or other specific group within the school, they would have reported on friendships that were more similar to those in the Grotpeter and Crick (1996) and Murray-Close et al. (2007) studies.

Although not a specific hypothesis, for monomethod self-reports for dyadic relationships of girls in both the community and school samples, it was found that the more girls report engaging in bullying, the more they also report experiencing bullying as a victim. This was also seen with monomethod peer-reports for the community sample. The more girls reported their friend engages in bullying the more they reported that friend is also a victim. Overall, these findings further support the idea of bully-victims, or children who are both aggressive toward others and bullied themselves, existing with relational aggression. Although the concept of a bully-victim has been supported with regard to physical aggression (Frisen, Jonsson, \& Persson, 
2007; Wang et al., 2009), there is also growing interest in this concept for relational aggression. Research that has been done has concluded that roughly $30 \%$ of children involved in relational aggression are both bullies and victims (Crick \& Bigbee, 1998). Additionally, a longitudinal analysis of adolescent relationships conducted by Sijtsema et al. (2009) found that relationally aggressive girls selected friends who were similar in terms of level of relational aggression. Relational aggression was also found to be learned from relationally aggressive friends. That is, girls who were friends with relationally aggressive girls increased their own level of relationally aggressive bullying over time. As such, it is possible the bully-victim pattern in friendships is a pervasive problem across ages and settings.

Similarly, although not a specific hypothesis, I found that for monomethod self-reports of both the community and school samples, the more girls disclose, the more they are a confidant to their friend. This pattern was also seen with the monomethod peer-reports, particularly with the community sample, where the more girls reported their friend discloses the more they also reported their friend was a confidant. Although there was no evidence of a significant correlation between disclosure and being a confidant with the school sample, there was a medium effect size for this correlation. These results suggests that disclosure is reciprocated from middle childhood into adolescence, although it may be more likely with younger children or in relationships developed outside of a school setting. Given that selfdisclosure is a positive way to build friendship when it is reciprocated (Derlega et al., 1993), it is not surprising that disclosure was reciprocated in these best friend dyads.

When examining the convergent validity correlations between the same trait across self and peer reports, only one of the four correlations was significant. For both the community sample and school sample, both members of the dyad agreed on the degree of victimization experienced. This finding suggests that victimization is likely more obvious to peers than the 
other constructs under consideration (aggression, being a confidant, and disclosure).

Surprisingly, there was little agreement between self and peer reports regarding relationships and what occurs between friends, with many non-significant correlations only having a small effect size. While it is understandable that girls may disagree on the level of disclosure within a friendship, as only the discloser knows how much information is shared compared to how much is withheld, aggression is more prominent and could be observed equally by all who witness it. This result is important for a few reasons. First, this finding suggests that children may not perceive their relationships the same as their peers do, even in a dyadic relationship. Further, previous studies have often used peer-reports of aggression and self-reports of friendship qualities or examined only the perspective of bullies. However, given that children may see their relationships differently from their best friend, this may limit what conclusions may be drawn from this approach.

\section{Friendship Networks}

Although hypothesized to be the same as peer groups, findings based on the friendship networks were actually more similar to those within a dyadic relationship. As with dyadic friendships, for friendship networks for both the community sample and the school sample, it was found that the more girls are victimized, the more they are also bullies themselves, further adding support that relational aggression is a pervasive problem. This study also adds to the recent research examining connected victimization (i.e., victimization that occurs within a friendship group). Recall that Zimmer-Gembeck et al. (2013) found that children who experienced higher levels of connected victimization also had higher levels of aggression themselves. This study supports that those involved in friendship networks who are also involved in relational aggression are likely to be both a victim and a bully. Additionally, this study found that girls who disclose to their friendship network are also a confidant for members of 
their friendship network. As with dyadic relationships, this is not surprising given the usefulness of self-disclosure in building relationships.

Further, as with dyadic relationships, hypotheses about bullying, victimization, disclosure, and being a confidant were largely not supported for either the community sample or the school sample. The one exception was a significant correlation showing that girls in the community sample who disclosed to girls in their friendship network were also bullied by those friends. Although Jones et al. (2011) had previously shown that that girls who experience the most relational aggression disclosed less to their friends than girls who did not experience relational aggression, this was not supported in this study. However, this finding does extend research by Grotpeter and Crick (1996) who also found this positive association for dyadic friendships. One explanation for this inconsistent result is that the current study used a more stringent approach to defining the friendship network by requiring participants to identify five friends and report on those specific friendships, compared to Jones et al. who allowed girls to think of all their friends without reporting a specific number when answering questions. It is likely that girls provided more specific accounts of their relationships when asked about individual friendships compared to when asked about all of their friendships. This study, therefore, examined relational aggression and self-disclosure in a relationship context that had not been specifically looked at previously.

Additionally, as this correlation was only found for the community sample, and not the school sample, it is possible this difference is due to the age differences, and corresponding developmental differences, between the samples. Friendships are ideal contexts for learning and practicing new social skills, but advanced social skills and understanding of social situations are often associated with adolescence more than childhood (Collins \& Steinberg, 2008). Collins and Steinberg (2008) stated that children and adolescents differ in their ability to participate in 
peer relationships, with adolescents being more skillful with conflict resolution and prosocial behaviors. Social relationships throughout childhood have allowed adolescents to develop the skills and knowledge necessary to establish and maintain positive relationships while discontinuing those that cause harm. Adolescents' increased focus on intimacy within friendships compared to children has also been associated with increased interpersonal competence and social adjustment for adolescents but not for preadolescents and younger children (Buhrmester, 1990). Views of conflict and support also change as children transition into adolescence, with children viewing support and conflict as different parts of a single construct, and adolescents viewing these as different constructs (Berndt \& Perry, 1986). Overall, these developmental differences indicate that adolescents, who have had more opportunities with social relationships, have a more developed understanding of friendship and social skills within a friendship, as well as a desire for more intimate friendships. As such, it is possible that the association between disclosure and victimization was not found for the school sample due to the greater importance placed on self-disclosure by adolescents, as well as adolescents' higher understanding of social skills and social competence. In particular, it is possible that those in the school sample have the skills and knowledge needed to develop high quality networks that include only those girls who provide supportive and positive friendships, whereas girls in the community sample are still building the skills to monitor their friendships.

Alternatively, this difference between the community sample and school sample might indicate that although girls are experiencing relational aggression in their friendship networks, it might be more related to what they are doing rather than what they are saying, especially within a school setting. For example, relational aggression is one way for girls to establish dominance in what is important to them, their peer relationships (Artz, 1998). Morretti, Holland, and McKay (2001) found that girls who have a negative self-representation, or a negative view 
of themselves, are more likely to try to manipulate and control the social environment than are girls who view themselves positively. They stated that one reason girls engage in relational aggression is to punish girls who had betrayed or hurt them. Following this line of reasoning, it is possible that relational aggression within some friendship networks may have less to do with what girls are sharing with each other and more to do with other aspects of relational aggression, such as denying friendship or spreading lies or rumors based on the actions of girls within the group. Additionally, given that often children try to establish dominance in their social hierarchies, relational aggression associated with behaviors that are less intimate than self-disclosure (i.e., making another girl mad) might be especially prominent when friendship networks are more dynamic and experience more frequent change. Given the larger size of the school sample compared to the groups within the community sample, as well as the greater chance for changes within the peer group that could influence friendship networks (i.e., large number of students entering and leaving the school every year, changes in class schedules throughout the year, opportunities to participate in multiple extracurricular activities throughout the year, etc.), it is possible that the girls in the school sample may be experiencing more frequent changes within their friendship networks and experience relational aggression that is more associated with girls' actions, rather than their disclosure.

\section{Peer Groups}

Although the same hypotheses were made regarding friendship networks and peer groups, results from the peer group showed a different pattern with regard to bullying, victimization, disclosure, and being a confidant. Within the peer group, for the community sample only, it was found that girls who were identified as a bully were also identified as disclosing to others. This was contrary to my hypothesis that bullies would be less likely to disclose. One reason for this finding may be that bullies are often popular and well know among 
their peers (Witvliet et al., 2009). They may also be seen as being more social, even if they are not well liked. As such, their other behaviors, such as disclosing to others, may be more noticeable within the peer group than the behaviors of children who are not as popular. It is also possible that this disclosure was used to illicit disclosure from potential targets of relational aggression. However, bullies were not more likely to be confidants, suggesting peers are not more likely to disclose to those who were identified as a bully. Additionally, the association between bullying and disclosing was not seen with the school sample, suggesting this behavior might be more visible with smaller peer groups.

Although results concerning dyadic friendships and friendship networks showed girls who disclosed were also confidants, only with the school sample was it found that girls who were identified as disclosing were also identified as being a confidant in the peer group. One explanation for this is, as stated previously, adolescents have more advanced social skills and place more value in intimacy and disclosure (Buhrmester \& Prager, 1995; Collins \& Steinberg, 2008). Older children and adolescents are also more likely to follow a norm of reciprocity. It would therefore be more likely for the girls in the school sample to reciprocate disclosure in the larger and more complex social setting of the peer group than it would be for the girls in the community sample. It is also possible that due to the girls in the community sample seeing each other less than those in the school sample, disclosing and being a confident within the peer group does not occur at the same frequency as it does with the school sample. As mentioned earlier, it is also possible that girls in the community sample share more of the same interests, beliefs, and values. Although this possibility could mean girls in the community sample might be more likely to disclose as their confidants would likely understand and agree with what they are disclosing, it might also make disclosure less necessary for building friendship as there could be an understanding that everyone already shares many of the same beliefs and thoughts. For the 
school sample, though, the size of the peer group, along with the higher degree of heterogeneity among the girls could increase the importance of disclosure and being a confidant for the purpose of finding peers with similar interests and values and building friendships with these girls.

Additionally, analyses of the school sample showed that girls who were frequently identified as a victim were also reported by their peers to disclose to others frequently. As with the friendship network, this finding is in contrast to my hypotheses and to results found by Jones et al. (2011) who found a negative correlation between victimization and disclosure in the peer group, but replicates research from Grotpeter and Crick (1996) who found this positive association among dyadic relationships. However, given that this correlation was only found for the school sample, it is possible that disclosure and being a victim are more likely to occur in either a larger peer group or a peer group characterized by a higher degree of heterogeneity.

Although results from dyadic friendships and friendship networks showed that girls who were more likely to engage in bullying were also more likely to be victimized, this pattern was not seen with the peer group. Given the larger size of the peer groups compared to the friendship networks and dyads, it is possible that those who experience victimization in this context are ignored or denied entry into smaller and more cohesive groups rather than experiencing more intimate forms of relational aggression. By being denied entry to these groups, girls have fewer opportunities to reciprocate bullying. This is supported by research conducted by Zimmer-Gembeck et al. (2013) who, in addition to examining connected victimization, also examined isolated victimization, or victimization that occurs when the victim is not well-liked by peers and rejected from the peer group. They found that children who experience isolated victimization, such as by being ostracized, are less likely to also engage in bullying themselves. Again, given the larger size of the peer group compared to friendship 
networks and dyadic friendships, it is likely that girls experience more isolated victimization within the peer group and, therefore, are less likely to also be a bully.

\section{Summary of Results: Comparing Two Samples and Three Relationship Contexts}

Overall, there were many similarities between the community sample and the school sample, especially regarding the association between bullying and victimization and the association between disclosing and being a confidant within a dyadic friendship and a friendship network. Even though there were differences regarding peer-reported victimization and selfreported aggression, and peer-reported disclosure and being a confidant (although both correlations did show a medium effect size), the majority of differences between the community and school samples occurred at the level of the peer group. This distinction is likely due to that fact that dyadic relationships and friendship networks were defined in both samples by a specific number of friends, one friend and up to five friends, respectively, whereas the peer groups were dependent by the number of girls in each group. Therefore, what was being assessed in a dyadic relationship or friendship network of a girl in the community sample was more similar to that of a girl in the school sample than was that girl's experience within her peer group compared to the school sample peer group. With this in mind, it understandable that the more different the group, the more likely girls will have different experiences.

The correlations at the level of the peer group also showed more differences compared to the correlations found at the level of dyadic relationships and friendship networks, whereas correlations for friendship networks were more similar to those at the level of the dyad. For example, although the bully-victim correlation was significant with dyadic friendships and friendships networks for both the school and community samples, there was no evidence that this correlation was significant for the peer group of either sample. There was also a significant correlation for the peer group that was not significant for most other levels of friendship. One 
possible explanation for these differences is that children's relationships with those in their peer group are much more different from their networks than expected. It was anticipated that experiences in the peer group would be similar to experiences in the friendship network, given their large size and larger number of interactions among girls compared to dyadic friendships. However, these findings suggest that friendship networks share more relationship characteristics with dyadic friendship. This similarity may be due to the higher level of intimacy between the five friends included in the network, compared to that found among a girl and other girls in the entire peer group.

\section{Limitations}

This study is not without limitations. First, the two samples included participants from two different age groups. Whereas participants in the community sample were primarily in middle childhood to early adolescence, all of the participants in the school sample were adolescents. However, it is difficult to attribute differences between the community sample and school sample solely to differences in age due to other differences between the groups. For example, in addition to differences with age, there were also differences in the sizes of the samples, the frequency with which participants saw each other, and being in a school compared to a community organization.

With regard to the size of the samples, although the overall combined sample included nearly 100 participants, the size of the community sample and the size of the school sample were both smaller and could not be meaningfully combined into a single sample because of their differences. Further, within the community sample, each individual group was small, and the number of girls in each group varied. For the school sample, although only one group was assessed, the group was much larger than any of the community groups. Although the varied sizes of the community sample groups were accounted for when analyzing data for the peer 
group, it is possible that groups of different sizes experience different amounts of aggression or disclosure between individual members or the group overall. While the high degree of similar findings between the school and community samples supports that girls are having the same experiences despite the size of their group, it is possible that the dynamics might change related to the size of the group.

Additionally, although this study expanded on previous studies by seeking the opinions of multiple girls involved in reciprocal relationships, as well as girls in friendship networks and the peer group, it is possible that girls responded in a way that would make either themselves or their overall friendship appear more positive than it is. This possibility could include rating positive items higher and negative items lower. It is also possible girls consistently rated themselves and their friends as either high on all items or low on all items, influencing their overall data. However, as relational aggression and disclosure are often unnoticed by teachers and adults because of the covert nature of many types of relational aggression and disclosure often occurring away from others, self-reports remain the best approach to understanding children's experiences with relational aggression.

Another limitation involves the friendships this study could assess. First, this study only examined the friendship of girls with other girls and did not assess friendships of boys, mixedgender friendships, or romantic relationships. This study also did not have a specific measure of closeness. Although this study had participants rank their top-rated friendships, one participant could have been much closer with her top-ranked friend than another participant was with her top-ranked friend. Additionally, for the community sample, the sizes of the groups were small, but most group members participated in the study. However, for the school sample, many students at the participating school did not participate in the study. This low response rate could have limited the friendships on which girls were able to report. It is possible that friendship 
dynamics would have been different with a larger percentage of girls from the participating school. Additionally, while attempts were made to match every girl with a top ranked peer for dyadic relationships and this was possible for the majority of participants, this was not possible for all girls. It is possible these unmatched girls' friends did not participate in the study or that the relationships these girls have with the other participants are somehow different from the relationships of girls who did have a match. However, the goal of this study was to address relational aggression occurring within various types of relationships and not just within interactions between girls. As such, this study needed to match girls with others who were also completing the survey. Further, given the high degree of similar findings between the school sample and the community sample, it seems possible that the girls who did participate are experiencing many of the same dynamics within their relationships.

Further, there are also limitations regarding data analyses. For this study, I chose to analyze data for dyads, friendship networks, and peer groups independent of each other by looking at correlations among the variables for each friendship context. By using a multitraitmultimethod approach for dyadic relationships, I was able to examine both peer and selfreports on a single relationship. However, this approach does not account for the girls and groups being nested within the community sample (this does not apply to the school sample as only one group was included). The correlation coefficients within the mulitrait-multimethod analysis do not account for the possibility that there might be differences between these groups as members of one group are likely more similar to other members of the same group than they are to members of a different group (Kahn, 2011). For example, it is possible that the members of one group might be more social or more cohesive than members of another group, which could influence how girls relate to each other. The challenges with this type of multilevel data structure also apply to the friendship networks and peer groups of the community sample. 
Despite this concern, to my knowledge, there is no method for computing Pearson correlation coefficients to account for this multilevel data structure. I attempted to address this problem within the peer groups by standardizing data for each group (given that the number of peer nominations would be a function of the number of girls in each group), but this does not eliminate the possibility that group differences may influence the data.

\section{Implications for Future Research}

With relational aggression among children continuing to rise and the effect it can have on girls' friendships, it is important to continue exploring girls' experiences with relational aggression and self-disclosure. First, researchers should continue to seek an understanding of relational aggression by addressing the experiences of both girls who engage in bullying and those who are victimized. This focus is especially important as this study supports the idea of bully-victims with relational aggression and the low agreement between girls and their friends regarding their friendship. It is also important to address what factors within friendships make girls more likely to experience relational aggression. Although this study did not support previous research showing that girls who disclose more to their friends are more likely to be victimized, differences in the samples, including peer group composition and length of friendships, might have important affects on the association between relational aggression and self-disclosure. Examining these differences may provide a better understanding of the complex association between sharing private information with friends and experiencing relational aggression from those friends. For example, it is possible that girls who have more differences and fewer similarities with their friends may be at greater risk for having their disclosure used against them. It is also possible that relational aggression associated with self-disclosure might be more prominent at certain points in friendship development, such as early in the friendship or when networks or peer groups experience changes with members. 
Similarly, this study focused on a broad definition for disclosure (i.e., sharing secrets, sharing private information). Although this is helpful for understanding girls' disclosure overall, future research could benefit from a more specific approach to understanding how different types of disclosure, or the specific content of disclosure, may be related to experiencing relational aggression. Following research that has shown that disclosure can and does change throughout a friendship, such as Collins and Miller (1994) showing that increasing the depth of disclosure has different outcomes than does increasing the breadth of disclosure, as well as Buhremester and Prager (1995) showing that different types of disclosure are typically present in each friendship stage, it is possible that changes in disclosure are also associated with changes in the form of relational aggression a girl may experience. For example, sharing secrets may be more strongly associated with experiencing relational aggression than is sharing one's views on a specific topic. It is also possible that different types of disclosure could be associated with different forms of relational aggression, such as having a friend threaten to end a friendship compared to being manipulated by having a friend threaten to share a secret. However, this needs to be specifically examined to understand how different types of disclosure are associated with different forms of aggression. Similarly, future research should also examine other potential factors that could increase the likelihood that a child might inhibit their disclosure or try to elicit disclosure from others related to use of relational aggression in the friendship.

Future research should also continue to address how experiences with relational aggression and self-disclosure may change over time, especially into adolescence during the high school years. Although Murray-Close et al. (2007) followed students from fourth to fifth grade, a longer longitudinal study that follows girls through high school could provide valuable information regarding the course of relational aggression and self-disclosure between friends. 
Further, as it is believed that physical aggression increases as students enter middle school due to students having a different peer group and trying to reestablish social dominance, but that victimization actually decreases during this time (Pelligrini \& Long, 2002), a study that follows girls as they transition from elementary school to middle school or middle school to high school could provide information on how the disclosure-aggression dynamic changes at key points in children's lives.

Additionally, future research should seek to include boys' experiences with relational aggression. Although boys engage in less relational aggression than do girls starting around elementary school, boys do engage in relational aggression with others, and understanding their experiences will provide valuable information regarding relational aggression and self-disclosure overall. Further, as older children and adolescents develop more mixed-gender friendships and start to develop romantic relationships, research should address relational aggression and selfdisclosure within these contexts.

Future research should also aim to include relational aggression experienced through cyberbullying and how self-disclosure might be related to relational aggression through electronic means. Research suggests that cyberbullying often occurs between existing offline social networks but includes a degree of anonymity to hide the identity of the aggressor (Vandebosch \& Cleemput, 2008). Research has also shown that those who engage in cyberbullying may have different motivations than those who engage in other types of aggression, such as releasing one's own negative feelings with cyberbullying rather than victimizing others based on characteristics of the victim with physical aggression (Parris, Varjas, Meyers, \& Cutts, 2012). Further, the power imbalance present in other forms of bullying may not be present with cyberbullying, as bullies have reported their victims have been of a lower social status, of the same social status, and of a higher social status (Vandebosch \& Cleemput, 
2008). Given these differences, it is possible that self-disclosure may be associated differently with relational aggression using electronic means compared to relational aggression in person.

Finally, future research should consider addressing the issues of relational aggression and self-disclosure with data analyses techniques that have not yet been utilized to examine this association. For example, data from a round-robin approach could be analyzed using social relations modeling (i.e., SOREMO) to provide additional and valuable information regarding the nature of relational aggression and self-disclosure within friendships. With this type of approach, every girl in a specific group describes her relationship with every other girl in the group. This would, therefore, allow researchers to look at how girls typically behave with others in their group, the response they typically get from others, and their behavior in specific dyadic relationships beyond their typical behavior.

\section{Implications for Theory and Practice}

Overall, this study did not support previous findings that self-disclosure is associated with children's experiences with relational aggression. As such, it is important to consider that self-disclosure is one possible factor in girls' experiences with relational aggression, but also consider that other factors, such as duration of the friendship, age of the girls, or where the friendship is formed may also influence how likely it is girls will experience aggression associated with their disclosure. While previous research with elementary school students found a correlation between sharing secrets and experiencing relational aggression, older students' experiences might be more associated with other aspects of relationships, such as competition in sports or academic standing.

The exception to this pattern was when examining the peer-group relationships among the school sample and the friendship network relationships among the community sample. With these groups, findings did support the association between relational aggression and self- 
disclosure. For the school-sample peer group and community-sample friendship networks only, the more girls were reported to disclose, the more they were reported to be victimized. As this supports previous research, this finding suggests that self-disclosure does need to be considered as a potential risk factor for experiencing relational aggression in some settings. Given the composition of students in the current school sample and previous research, it is possible that relational aggression associated with self-disclosure in the peer group is more problematic among girls with fewer similarities or in more heterogeneous settings, such as in a classroom or a school. This information is valuable for those working with groups of students as it highlights the importance of helping girls build relationships based on identifying their similarities. In many schools, this could mean implementing programs to help those who would not typically interact due to various reasons (age, race, social status, socio-economic status, etc.) develop an understanding and appreciation for each other based on finding what they have in common. If individual differences potentially increase the risk for experiencing relational aggression when disclosing, highlighting similarities could potentially decrease this risk.

This study also showed that, according to self-reports for dyads, friendship networks, and peer groups, the more girls engage in bullying the more likely they are to be victimized. As such, it is important to recognize that relational aggression is not an isolated event but is happening between girls who consider each other friends. Although these girls may consider this reciprocal bullying part of their friendship, they are still at risk for experiencing the negative outcomes associated with poor peer relationships. Therefore, parents, teachers, and others who work with children should be aware that being a bully does not mean a child is not also a victim, and girls with close friends may still experience bullying. Further, schools should consider addressing the issue of relational aggression with the entire school, or at Tier 1 if using a Response to Intervention or Multi-tiered System of Supports model, incorporating the social 
ecology of the school when developing or implementing anti-bullying programs. This observation means that schools should establish a school-wide system that incorporates students, teachers, administrators, and parents to educate students about what relational aggression is, the harm it can cause, and what students can do to support themselves and each other. Often schools take a reactive approach to bullying, addressing the issue with those of have bullied others or trying to help those who have been victimized. However, a proactive approach targeting the school as a system could reduce bullying that is already happening and potentially prevent future bullying by empowering all students to stand up for themselves and their peers (Bradshaw, 2013; Schroeder et al., 2012).

Based on the heteromethod reports for dyadic relationships, there was very little overlap between what one girl reported about her friendship and what her friend reported about the same friendship. Girls in both the school sample and community sample only agreed on peer- and self-reported victimization. Girls in the community group also agreed on peerreported aggression and self-reported victimization. This lack of overlap is important because it suggests that girls, even within the same friendship, have different opinions and views of what is occurring within the relationship. Schools and those tasked with developing anti-bullying programs can use this information to better address relational aggression by understanding that girls may see their relationships differently and incorporating this into their program. An approach to reducing bullying among girls would benefit from open discussion to allow girls to share their opinions and views, thereby increasing understanding among girls. 


\section{REFERENCES}

Adams, R. G., \& Blieszner, R. (1994). An integrative conceptual framework for friendship research. Journal of Social and Personal Relationships, 11, 163-184. doi: $10.1177 / 0265407594112001$

Altman, I. \& Taylor, D. (1973). Social penetration: The development of interpersonal relationships. New York: Holt, Rinehart \& Winston.

Antaki, C., Barnes, R., \& Leudar, I. (2005). Self-disclosure as a situated interactional practice. British Journal of Social Psychology, 44, 181-199. doi: 10.1348/014466604X15733

Archer, J., \& Coyne, S. M. (2005). An integrated review of indirect, relational, and social aggression. Personality and Social Psychology Review, 9, 212-230. doi: 10.1207/s15327957pspr0903_2

Berg, J. H., \& Clark, M. S. (1989). Differences in social exchange between intimate and other relationships: Gradually evolving or quickly apparent? In V. J. Derlega \& B. A. Winstead (Eds.), Friendship and Social Interaction (pp. 101-128). New York, NY: Springer Verlag.

Berndt, T. J., \& Perry, T. B. (1986). Children's perceptions of friendships as supportive relationships. Developmental Psychology, 22, 640-648. doi: 10.1037//00121649.22.5.640

Bradshaw, C. P. (2013). Preventing bullying through positive behavioral interventions and supports (PBIS): A multitiered approach to prevention and integration. Theory into Practice, 52, 288-295. doi: 10.1080/00405841.2013.829732

Buhrmester, D. (1990). Intimacy of friendship, interpersonal competence, and adjustment during preadolescence and adolescence. Child development, 61, 1101-1111. doi: $10.2307 / 1130878$

Buhrmester, D., \& Prager, K. (1995). Patterns and functions of self-disclosure during childhood and adolescence. In K. J. Rotenberg (Ed.), Disclosure processes in children and adolescents (10-56). Cambridge: Cambridge University Press.

Bukowski, W. M., Hoza, B., \& Boivin, M. (1994). Measuring friendship quality during pre- and early adolescence: The development and psychometric properties of the friendship qualities scale. Journal of Social and Personal Relationships, 11, 471-484. doi: 10.1177/0265407594113011 
Campbell, D. T., \& Fiske, D. (1959). Convergent and discriminant validity by multitraitmultimethod matrix. Psychological Bulletin, 56, 81- 105. doi: 10.1037/h0046016

Casey-Cannon, S., Hayward, C., \& Gowen, K. (2001). Middle-school girls' reports of peer victimization: Concerns, consequences, and implications. Professional School Counseling, 5(2), 138-153.

Christophe, V., \& Rime, B. (1997). Exposure to the social sharing of emotion: Emotional impact, listener responses and secondary social sharing. European Journal of Social Psychology, 27, 37-54. doi: 10.1002/(SICI)1099-0992(199701)27:1<37::AID-EJSP806>3.0.CO;2-1

Cillessen, A., Jiang, X. L., West, T., \& Laszkowski, D. (2005). Predictors of dyadic friendship quality in adolescence. International Journal of Behavioral Development, 29, 165-172. doi: 10.1080/01650250444000360

Cohen, J. (1992). A power primer. Psychological Bulletin, 112, 155-159. doi: 10.1037/00332909.112.1.155

Collins, N., \& Miller, L. (1994). Self-disclosure and liking: A meta-analytic review. Psychological Bulletin, 116, 457-475. doi: 10.1037/0033-2909.116.3.457

Collins, W. A., \& Steinberg, L. (2006). Adolescent development in interpersonal context. In W. Damon \& R. M. Lerner (Eds.), Handbook of child psychology (pp. 551-590). Hoboken, NJ: Wiley \& Sons, Inc.

Coates, D., \& Winston, T. (1987). The dilemma of distress disclosure. In V. J. Derlega \& J. H. Berg (Eds.), Self-disclosure: Theory, research, and therapy (pp. 229-255). New York, NY: Plenum Press. doi: 10.1007/978-1-4899-3523-6_11

Cozby, P. C. (1973). Self-disclosure: A literature review. Psychological Bulletin, 79, 73-91. doi: $10.1037 /$ h0033950

Crick, N. R. \& Bigbee, M. A. (1998). Relational and overt forms of peer victimization: A multiinformant approach. Journal of Counseling and Clinical Psychology, 66, 337-347. doi: 10.1037//0022-006X.66.2.337

Crick, N. R., Bigbee, M. A., \& Howes, C. (1996). Children's normative beliefs about aggression: How do I hurt thee? Let me count the ways. Child Development, 67, 1003-1014. doi: $10.2307 / 1131876$

Crick, N. R., Casas, J. F., \& Ku, H. (1999). Relational and physical forms of peer victimization in preschool. Developmental Psychology, 35, 376 - 385. doi: 10.1037/0012-1649.35.2.376

Crick, N. R., \& Grotpeter, J. K. (1995). Relational aggression, gender, and social-psychological adjustment. Child Development, 66, 710-722. doi: 10.2307/1131945 
DePaulo, B. M., \& Kashy, D. A. (1998). Everyday lies in close and casual relationships. Journal of Personality and Social Psychology, 74, 63-79. doi: 10.1037//0022-3514.74.1.63

DePaulo, B. M., Kashy, D. A., Kirkendol, S. E., Wyer, M. M., \& Epstein, J. A. (1996). Lying in everyday life. Journal of Personality and Social Psychology, 79, 979-995. doi: 10.1037//0022-3514.70.5.979

Derlega, V., Metts, S., Petronio, S., \& Marqulis, S. T. (1993). Self-disclosure. Newbury Park, CA: Sage Publications, Inc.

Derlega, V. J., \& Grzelak, J. (1979). Appropriateness of self-disclosure. In: G. J. Chelune (Ed.), Selfdisclosures: Origins, patterns and implications of openness in interpersonal relationships (pp. 151-176). San Francisco, CA: Jossey-Bass.

Galen, B. R., \& Underwood, M. (1997). A developmental investigation of social aggression among girls. Developmental Psychology, 33, 589-599. doi: 10.1037/0012-1649.33.4.589

Grotpeter, J K., \& Crick, N.R. (1996). Relational aggression, overt aggression, and friendship. Child Development, 67, 2328-2338. doi: 10.2307/1131626

Gottman, J, M. (1983). How children become friends. Monographs of the Society for Research in Child Development, 48, 1-86. doi: 10.2307/1165860

Hallinan, M. T. (1980). Patterns of cliquing among youth. In H. C. Foot, A. J. Chapman, \& J. R. Smith (Eds.), Friendship and peer relations in children (pp. 321-342). New York, NY: Wiley.

Hall, K. R. (2006). Using problem-based learning with victims of bullying behavior. Professional School Counseling, 9, 231-238.

Henington, C., Hughes, J. N., Cavell, T. A., \& Thompson, B. (1998). The role of relational aggression in identifying aggressive boys and girls. Journal of School Psychology, 36, 457-477. doi: 10.1016/S0022-4405(98)00015-6

Ichiyama, M. A., Colbert, D., Laramore, H., Heim, M., Carone, K., \& Schmidt, J. (1993). Selfconcealment and correlates of adjustment in college students. Journal of College Student Psychotherapy, 7, 55- 68.

Jones, J. L., Kahn, J. H., Landau, S. (2011, February). Children's Self-Disclosure Patterns as a Predictor of Relational Aggression. Poster session presented at the National Association for School Psychologists in San Francisco, CA.

Joinson, A. N. (2001). Self-disclosure in computer-mediated communication: The role of selfawareness and visual anonymity. European Journal of Social Psychology, 31, 177-192. doi: 10.1002/ejsp.36 
Jourard, S. M., \& Lasakow, P. (1958). Some factors in self-disclosure. Journal of Abnormal and Social Psychology, 56, 91-98. doi: 10.1037/h0043357

Kahn, J. H. (2011). Multilevel Modeling: Overview and applications to research in counseling psychology. Journal of Counseling Psychology, 58, 257-271. doi: 10.1037/a0022680

Kashy, D. A., \& DePaulo, B. M. (1996). Who lies?. Journal of Personality and Social Psychology, 70, 1037-1051. doi: 10.1037//0022-3514.70.5.1037

Kelly, A. E., \& McKillop, K. J. (1996). Consequences of revealing personal secrets. Psychological Bulletin, 120, 450-465. doi: 10.1037//0033-2909.120.3.450

LaFontana, K. M., \& Cillessen, A. H. N. (2002). Children's perceptions of popular and unpopular peers: A multi- method assessment. Developmental Psychology, 38, 635-647. doi: 10.1037/0012-1649.38.5.635

Laurenceau, J., Barrett, L. F., \& Pietromonaco, P. R. (1998). Intimacy as an interpersonal process: The importance of self-disclosure, partner disclosure, and perceived partner responsiveness in interpersonal exchanges. Journal of Psychology and Social Psychology, 74, 1238-1251. doi: 10.1037//0022-3514.74.5.1238

Lepore, S. J., Ragan, J. D., \& Jones, S. (2000). Talking facilitates cognitive-emotional processes of adaptation to an acute stressor. Journal of Personality and Social Psychology, 78, 499508. doi: 10.1037/0022-3514.78.3.499

Miller, L. C., Berg, J. H., \& Archer, R. L. (1983). Openers: Individuals who elicit intimate selfdisclosure. Journal of Personality and Social Psychology, 44, 1234-1244. doi: 10.1037/0022-3514.44.6.1234

Murray-Close, D., Ostrov, J. M., \& Crick, N. R. (2007). A short-term longitudinal study of growth of relational aggression during middle childhood: Associations with gender, friendship intimacy, and internalizing problems. Development and Psychopathology, 19, 187-203. doi: 10.1017/S0954579407070101

Newcomb, A. F., \& Bagwell, C. L. (1995). Children's friendship relations: A meta-analytic review. Psychological Bulletin, 117, 306-347. doi: 10.1037/0033-2909.117.2.306

Nishina, A., Juvonen, J., \& Witkow, M. R. (2005). Sticks and stones may break my bones, but names will make me feel sick: The psychosocial, somatic, and scholastic consequences of peer harassment. Journal of Clinical Child and Adolescent Psychology, 34, 37-48. doi: 10.1207/s15374424jccp3401_4

Pellegrini, A. D., \& Long, J. D. (2003). A sexual selection theory longitudinal analysis of sexual segregation and integration in early adolescence. Journal of Experimental Child Psychology, 85, 257-278. doi: 10.1016/S0022-0965(03)00060-2 
Prinstein, M. J., Boergers, J., \& Vernberg, E. M. (2001). Overt and relational aggression in adolescents: Social-psychological adjustment of aggressors and victims. Journal of Clinical Child Psychology, 30, 479-491. doi: 10.1207/S15374424JCCP3004_0

Rose, A J., \& Rudolph, K. D. (2006). A review of sex differences in peer relationship processes: Potential trade-offs for the emotional and behavioral development of girls and boys. Psychological bulletin, 132, 98-131. doi: 10.1037/0033-2909.132.1.98

Rose, A. J., Swenson, L. P., \& Waller, E. M. (2004). Overt and relational aggression and perceived popularity: developmental differences in concurrent and prospective relations. Developmental Psychology, 40, 378-387. doi: 10.1037/0012-1649.40.3.378

Rotenberg, K. J. \& Mann, L. (1986). The development of the norm of the reciprocity of selfdisclosure and its function in children's attraction to peers. Child Development, 57, 1349-1357. doi: 10.2307/1130414

Savin-Williams, R. C., \& Berndt, T. J. (1990). Friendship and peer relationships. In S. S. Feldman \& G. R. Elliott (Eds.), At the threshold: The developing adolescent (pp. 277307). Cambridge, MA: Harvard University Press.

Schroeder, B. A., Messina, A., Schroeder, D., Good, K., Barto, S., Saylor, J. \& Masielli, M. (2012). The implementation of a statewide bullying prevention program: Preliminary findings from the field and the importance of coalitions. Health Promotion Practice, 13, 489-495. doi: $10.1177 / 1524839910386887$

Sutton, J., Smith, P. K., \& Swettenham, J. (1999). Social cognition and bullying: Social inadequacy or skilled manipulation? British Journal of Developmental Psychology, 17, 435-450. doi: 10.1348/026151099165384

Olweus, D. (1991). Bully/victim problems among school children: Basic facts and effects of a school based intervention program. In D. Pepler \& K. Rubin (Eds.), The development and treatment of childhood aggression (pp. 411-438). Hillsdale, NJ: Erlbaum.

Olweus, D. (2003). A profile of bullying at school. Educational Leadership, 60, 12-17.

Vandebosch, H., \& Van Cleemput, K. (2008). Defining cyberbullying: A qualitative research into the perceptions of youngsters. CyberPsychology \& Behavior, 11, 499-503. doi: 10.1089/cpb.2007.0042

Varjas, K., Talley, J., Meyers, J., Parris, L., \& Cutts, H. (2010). High school students' perceptions of motivations for cyberbullying: An exploratory study. Western Journal of Emergency Medicine, 11, 269-273.

Wang, J., lannotti, R. J. \& Nansel, T. R. (2009). School bullying among US adolescents: Physical, verbal, relational and cyber. Journal of Adolescent Health, 45, 368-375. doi: 10.1016/j.jadohealth.2009.03.021 
Werner, N. E., \& Grant, S. (2008). Mother's cognitions about relational aggression: Associations with discipline responses, children's normative beliefs, and peer competence. Social Development, 18, 77-98. doi: 10.1111/j.1467-9507.2008.00482.x

Witvliet, M., Olthof, T., Hoeksma, J. B., Goossens, F. A., Smits, M. S. I., \& Koot, H. M. (2009) Peer Group Affiliation of Children: The role of perceived popularity, likeability, and behavioral similarity in bullying. Social Development, 19, 285-303. doi: 10.1111/j.1467-

9507.2009.00544.x

Zimmer-Gembeck, M. J., Pronk, R. E., Goodwin, B., Mastro, S., Crick, N. R. (2012). Connected and isolated victims of relational aggression: Associations with peer group status and differences between girls and boys. Sex Roles, 68, 363-377. doi: 10.1007/s11199-0120239-y 
APPENDIX A

ITEMS INCLUDED IN PEER NOMINATION FORM

\section{Friendliness Toward Others}

This girl tires hard to be nice to everyone.

\section{Relational Aggression Bullying Item}

This girl leaves other girls out of activities when mad at them and tries to get back at girls by ignoring them, sharing their secrets, or spreading rumors.

\section{Relational Aggression Victimization Item}

This girl is left out of activities when others are mad at her and is ignored, has her secrets shared with others, and has rumors spread about her.

\section{Self-Disclosure to Others Item}

This girl tells other girls her secrets, problems, and things that make her sad

\section{Self-Disclosure from Others Item}

Other girls tell this girl about their secrets, problems, and things that make her sad. 


\section{APPENDIX B}

\section{COMMUNITY SAMPLE PARENT CONSENT FORM}

\section{Dear Parent:}

My name is Jayme Jones, and I am a Ph.D. student in the Department of Psychology at Illinois State University. I am conducting a research project that aims to investigate students' views of communication with friends and peer relationships. This study will help researchers gain a better understanding of how children and adolescents interact with each other. I am especially interested in young people's experiences with relational aggression. Relational aggression is a form of bullying that includes teasing, spreading rumors or lies with the intention of hurting, and purposely excluding others from group activities. Targets of relational aggression, who are typically girls, are often made fun of and excluded by their peers.

I am requesting your child's participation in completing a paper-and-pencil questionnaire in one session. This survey will include questions about your child's experiences with witnessing or experiencing prosocial behavior and relational aggression in her friendships and her selfdisclosure to friends. It will also include questions about relationally aggressive bullies and victims. The session should take 30-60 minutes and will be completed during the troop meeting. Your child's responses will be confidential. Also, your child will not need to put her name on the survey.

Your child's participation in this study is voluntary. If you choose not to have your child participate, there will be no penalty. Likewise, if your child chooses to participate and then decides to withdraw from the study at any time, there will be no penalty. The results of the research study may be published or presented at a conference, but your child's name will not be used. Your child's responses will be kept confidential. In other words, your child's name will not be on the survey, and only the research team will be allowed to see your child's responses. All data will be stored securely in a locked filing cabinet or on a computer accessible to only the researchers. Furthermore, all of the completed consent forms will be securely locked and stored in cabinets on the campus of Illinois State University.

RISKS. There may be some mild risks associated with participation in this study. Some children may find answering personal questions uncomfortable. All participants will have the option to skip any question they are not comfortable answering. There is also a minimal risk of loss of 
privacy. However, all participants will be assured that their individual responses will not be shared with anyone at the Girl Scouts, including leaders or peers.

BENEFITS. Your child may benefit directly from her involvement in this study. First, she will have the opportunity to be part of a large research project and may find her involvement in a psychological study interesting. In addition, results from this study, only in aggregate/averaged form, will be given to the Girl Scouts to potentially address concerns regarding relational aggression.

In order for your child to participate, please check that you provide consent and ask your child to return this form to her troop leader.

If you do not want your child to participate, please check that you do not provide consent and ask your child to return this form to her troop leader.

If you have any questions concerning this research study or your child's participation in the study, please call/email Jayme Jones at (217) 341-0916, jljone5@ilstu.edu, or email Dr. Jeffrey Kahn at jhkahn@ilstu.edu.

If you have any questions about you or your child's rights as a subject/participant in this research, or if you feel you or your child have been placed at risk, you can contact the Research Ethics \& Compliance Office at Illinois State University at (309) 438-2529 or rec@ilstu.edu.

The researchers believe the issue of relational aggression is very important. We hope that you consider this opportunity and provide consent for your daughter to participate.

Thank you,

Jayme Jones

Ph.D. Candidate in School Psychology

Troop Number:

Troop Leader's Name:

Child's Name:

Age: Grade: I give consent for my child to participate in the above study. I do not give consent for my child to participate in the above study. 
Name of Parent/Guardian (Please Print)

Signature of Parent/Guardian

Date 


\section{APPENDIX C}

\section{COMMUNITY SAMPLE ASSENT FORM}

You are invited to participate in a research study on what girls are like today. I am especially interested in what girls think and feel about your friendships, how you feel you get along with your friends, and what information you share with your friends.

Your parent has already given you permission to participate. If you want to participate, you will be given some questions to be answered in one session lasting about 20-30 minutes. This will begin as soon as you agree to participate. Your answers will be confidential. This means that your name will not be on any of the papers, and only members of the research team will be able to read your answers. No one else, including your parents, troop leader, or other girls in your troop, will be able to read your answers.

There is some risk with participating in this study. Some girls may find that answering personal questions about themselves upsets them. The benefit to you is that you get to be a part of an important research project about girls.

You do not have to participate in this study if you don't want to. If you do participate, you can quit at any time. You may also skip any of questions that I ask you or ask for help if you feel uncomfortable. If you do not want to complete the survey, you will not be punished in any way. You may also take a survey and return it blank without answering any of the questions. Your privacy will be respected.

If you feel upset or uncomfortable about answering any question, you may skip that question or request assistance from a researcher.

If you have any questions about this study, please ask.

Please print and sign your name below if you agree to participate.

Participant's Name (Printed)

Grade 
Participant's Signature

Date 


\section{APPENDIX D}

\section{COMMUNITY SAMPLE DEBRIEFING FORM}

Thank you for your participation in this survey. The researchers are interested in learning about aggression between girls and how girls talk to their friends. The researchers are interested in teasing, spreading rumors or lies with the intention of hurting, and purposely excluding others from group activities. The purpose of this study is to look at whether girls who talk more with their friends experience more teasing. Your participation has provided valuable information that will help inform the Illinois State University research team about this important topic.

Many of the questions you answered were very personal, and some girls may find them uncomfortable to answer. If answering any of these questions led you to feel uncomfortable or distressed and you would like to speak to someone about your thoughts, please contact Ms. Jayme Jones.

If you have any questions about this study or if you would like more information following the completion of this study, please feel free to contact Ms. Jayme Jones (jljone5@ilstu.edu, (217) 341-0916) or Dr. Jeffrey Kahn (jhkahn@ilstu.edu, (309) 438-7939).

If you have any complaints or concerns about this research, please feel free to contact the Research Ethics \& Compliance Office at Illinois State University at (309) 438-2520.

Thank you for participating! 
APPENDIXE

SCHOOL SAMPLE PARENT CONSENT FORM

\section{Dear Parent:}

My name is Jayme Jones, and I am a Ph.D. student in the Department of Psychology at Illinois State University. I am conducting a research project that aims to investigate students' views of communication with friends and peer relationships. This study will help researchers gain a better understanding of how children and adolescents interact with each other. I am especially interested in young people's experiences with relational aggression. Relational aggression is a form of bullying that includes teasing, spreading rumors or lies with the intention of hurting, and purposely excluding others from group activities. Targets of relational aggression are often made fun of and excluded by their peers.

I am requesting your child's participation in completing a paper-and-pencil questionnaire at school in one session. This survey will include questions about your child's experiences with witnessing or experiencing relational aggression in his or her friendships and self-disclosure to friends. It will also include questions about relationally aggressive bullies and victims at school. The session should take 30 minutes and will take place during a session in January. Your child's responses will be confidential. Also, your child will not need to put his or her name on the survey.

Your child's participation in this study is voluntary. If you choose not to have your child participate, there will be no penalty. Likewise, if your child chooses to participate and then decides to withdraw from the study at any time, there will be no penalty. The results of the research study may be published or presented at a conference, but your child's name will not be used. Your child's responses will be kept confidential. In other words, your child's name will not be on the survey, and only the research team will be allowed to see your child's responses. All data will be stored securely in a locked filing cabinet or on a computer accessible to only the researchers. Furthermore, all of the completed consent forms will be securely locked and stored in cabinets on the campus of Illinois State University.

RISKS. There may be some mild risks associated with participation in this study. Some children may find answering personal questions uncomfortable. All participants will have the option to skip any question they are not comfortable answering. In the event that your child becomes upset she or he may speak with one of the researchers who will be on site during the data 
collection. Alternatively, your child may speak with their guidance counselor about this experience. There is also a minimal risk of loss of privacy. However, all participants will be assured that their individual responses will not be shared with anyone at their school, including teachers, administrators, or other students.

BENEFITS. Your child may benefit directly from his involvement in this study. First, he or she will have the opportunity to be a part of a large research project and may find involvement in a psychological study interesting. In addition, results from this study, only in aggregate/averaged form, will be given to the school building principal to potentially address concerns regarding relational aggression at school.

In order for your child to participate, please check that you provide consent and ask your child to return the second page of this form to his or her teacher or guidance counselor. Please keep the list of researcher contacts for your personal records.

If you do not want your child to participate, please check that you do not provide consent and ask your child to return this form to his or her teacher or guidance counselor.

Every student who returns a consent form, regardless of whether they receive consent will be entered into a drawing for an iTunes gift card. If you have any questions concerning this research study or your child's participation in the study, please call/email Jayme Jones at (217) 341-0916, jljone5@ilstu.edu, or email Dr. Jeffrey Kahn at jhkahn@ilstu.edu.

If you have any questions about you or your child's right as a subject/participant in this research, or if you feel you or your child have been placed at risk, you can contact the Research Ethics \& Compliance Office at Illinois State University at (309) 438-2529 or rec@ilstu.edu.

This project will be completed in January, 2014. We ask that consent forms be returned to the school by [date]. The researchers believe the issue of relational aggression is very important. We hope that you consider this opportunity and provide consent for your child to participate.

Thank you,

Jayme Jones

Ph.D. Candidate in School Psychology

Child's Name:

Grade:

I give consent for my child to participate in the above study. I do not give consent for my child to participate in the above study. 
Name of Parent/Guardian (Please Print)

Signature of Parent/Guardian

Date 


\section{APPENDIX F}

\section{SCHOOL SAMPLE ASSENT FORM}

You are invited to participate in a research study on what students are like today. I am especially interested in what students think and feel about your friendships, how you feel you get along with your friends, and what information you share with your friends.

Your parent has already given you permission to participate. If you want to participate, you will be given some questions to be answered in one session lasting about 45 minutes. This will begin as soon as you agree to participate. Your answers will be confidential. This means that your name will not be on any of the papers, and only members of the research team will be able to read your answers. No one else, including your parents, teachers, or peers, will be able to read your answers.

There is some risk with participating in this study. Some students may find that answering personal questions about themselves upsets them. If you feel upset you may speak with one of the researchers or your guidance counselor. The benefit to you is that you get to be a part of an important research project about students.

You do not have to participate in this study if you don't want to. If you do participate, you can quit at any time. You may also skip any of questions or ask for help if you feel uncomfortable. If you do not want to complete the survey, you will not be punished in any way. There will be no consequences from your teacher or school for not signing this form. You may also take a survey and return it blank without answering any of the questions. Your teacher will not know who has and who has not completed the survey. Your privacy will be respected.

If you feel upset or uncomfortable about answering any question, you may skip that question or request assistance from a researcher.

If you have any questions about this study, please ask.

Participant's Name (Printed)

Grade 


\section{APPENDIX G}

\section{SCHOOL SAMPLE DEBRIEFING FORM}

Thank you for your participation in this survey. The researchers are interested in learning about aggression between middle school students and how students talk to their friends. The researchers are interested in learning more about teasing, spreading rumors or lies with the intention of hurting, and purposely excluding others from group activities. The purpose of this study is to look at whether girls who talk more with their friends experience more teasing. Your participation has provided valuable information that will help inform the Illinois State University research team about this important topic.

Many of the questions you answered were very personal and some students may find them uncomfortable to answer. If answering any of these questions led you to feel uncomfortable or distressed and you would like to speak to someone about your thoughts, please contact Ms. Jayme Jones.

If you have any questions about this study or if you would like more information following the completion of this study, please feel free to contact Ms. Jayme Jones (jljone5@ilstu.edu, (217) 341-0916) or Dr. Jeffrey Kahn (jhkahn@ilstu.edu, (309) 438-7939).

If you have any complaints or concerns about this research, please feel free to contact the Research Ethics \& Compliance Office at Illinois State University at (309) 438-2520.

Thank you for participating! 